\title{
ANÁLISE DA GESTÃO DE RECURSOS HUMANOS SUSTENTÁVEL: UM ESTUDO EM UMA MULTINACIONAL
}

\section{ANALYSIS OF SUSTAINABLE HUMAN RESOURCE MANAGEMENT: A STUDY IN A MULTINATIONAL}

\section{MORGANA KLESENER}

Universidade Federal de Santa Maria (UFSM)

Bacharel em Administração - UFSM

Orcid: https://orcid.org/0000-0002-4008-0768

E-mail: mokle.klemo@gmail.com

Av. Roraima, 1000 - Cidade Universitária - Bairro Camobi - CEP: 97105-900 - Santa Maria (RS)

\author{
ROGER DA SILVA WEGNER \\ Universidade Federal de Santa Maria (UFSM) \\ Doutorando em Administração - PPG em Administração (UFSM) \\ Orcid: http://orcid.org/0000-0002-2034-8034 \\ E-mail: rswegnerr@gmail.com \\ MICHEL BARBOZA MALHEIROS \\ Universidade Federal de Santa Maria (UFSM) \\ Doutorando em Administração - PPG em Administração (UFSM) \\ Orcid: http://orcid.org/0000-0001-7076-4258 \\ E-mail: malheirosmb@gmail.com \\ VANESSA PIOVESAN ROSSATO \\ Universidade Federal de Santa Maria (UFSM) \\ Mestranda em Administração - PPG em Administração (UFSM) \\ Orcid: http://orcid.org/0000-0001-7165-4712 \\ E-mail: vanessapiovesan@yahoo.com.br \\ VANIA DE FÁTIMA BARROS ESTIVALETE \\ Universidade Federal de Santa Maria (UFSM) \\ Professora associada do Departamento de Ciências Administrativas - UFSM
}

Pós-doutorado em Sociologia Econômica das Organizações Instituto Superior de Economia e Gestão

da Universidade de Lisboa-Portugal (ISEG)

Orcid: http://orcid.org/0000-0002-3277-8613

E-mail: vaniaestivalete@ufsm.br

Submissão: 10/07/2020. Revisão: 22/01/2021. Aceite: 24/05/2021. Publicação: 01/07/2021.

DOI: http://dx.doi.org/10.22277/rgo.v14i3.5648

Este é um artigo publicado em acesso aberto (Open Access) sob a licença Creative Commons Attribution, que permite uso, distribuição e reprodução em qualquer meio, sem restrições desde que o trabalho original seja corretamente citado. 
Análise da gestão de recursos humanos sustentável: um estudo em uma multinacional

\title{
RESUMO
}

Como objetivo principal, este estudo visa desenvolver uma modelagem, a fim de elencar os principais indicadores que contribuem para a gestão de recursos humanos sustentável, sob a percepção dos colaboradores e gestores de uma multinacional. Assim, a pesquisa se caracteriza por ser descritiva, com abordagens qualitativas e quantitativas, utilizando o método Analytic Hierarchy Process (AHP). Por meio dos resultados apresentados, observouse que a empresa já possui uma política interna e valores voltados à sustentabilidade, o que facilita o trabalho para o desenvolvimento. Também se notou que os gestores e colaboradores possuem pontos de vista diferentes. A liderança, na visão dos gestores, é o critério que todos têm em comum como mais importante. Já na percepção dos colaboradores, o trabalho em equipe seria o critério mais importante para o desenvolvimento sustentável da organização. Dessa maneira, sugere-se que a empresa invista em capacitação de seus líderes quanto ao assunto "Equipe". Ademais, é preciso treinar os gestores de forma que eles consigam desenvolver, junto de uma equipe, estratégias que mantenham a empresa em constante desenvolvimento sustentável e que possam futuramente trazer inovações.

Palavras-chave: Sustentabilidade. Recursos Humanos. Modelagem.

\begin{abstract}
As a main objective, this study aims to develop a model to list the main indicators that contribute to sustainable human resource management, under the perception of employees and managers of a multinational. Thus, the research is characterized by being descriptive, with qualitative and quantitative approaches, using the Analytic Hierarchy Process (AHP) method. Through the results presented, it was observed that the company already has an internal policy and values focused on sustainability, which facilitates the work for development. It was also noted that managers and employees have different points of view. Leadership, in the view of managers, is the criterion that everyone has in common as the most important. In the employees' perception, teamwork would be the most important criterion for the sustainable development of the organization. Thus, it is suggested that the company invest in training its leaders on the subject "Team". In addition, it is necessary that it seeks to train managers so that they can develop, together with a team, strategies that keep the company in constant sustainable development and that can bring innovations in the future.
\end{abstract}

Keywords: Sustainability. Human Resources. Modeling.

\section{INTRODUÇÃO}

Com o passar dos tempos, a sociedade tem exigido das organizações um papel diferenciado em sua atuação, uma visão mais voltada para a sustentabilidade e um pensamento direcionado para a preservação e valorização dos colaboradores. Desta forma, para que se mantenham no mercado de modo competitivo, é necessário um pensamento moderno e evoluído, envolvendo tais aspectos. Neste contexto, a sustentabilidade e os recursos humanos $(\mathrm{RH})$ apresentam grande influência no desenvolvimento da organização para o alcance dos resultados (DIAZ-CARRION; LÓPEZ-FERNÁNDEZ; ROMERO-FERNANDEZ, 2020). Essa reflexão deve estar presente no planejamento da organização, para que estratégias possam ser desenvolvidas. Dessa forma, o planejamento torna-se o principal 
Morgana Klesener, Roger da Silva Wegner, Michel Barboza Malheiros, Vanessa Piovesan Rossato e Vania de Fátima Barros Estivalete

aliado para o crescimento da organização e para que os aspectos citados se façam presentes neste plano.

Mediante essa percepção e contribuindo para as discussões a respeito da sustentabilidade e RH, é importante destacar que muitas organizações não prezam pela sustentabilidade em seus processos e no modo em que atuam frente ao mercado e seus colaboradores (DIAZ-CARRON; LÓPEZ-FERNANDEZ; ROMERO FERNANDEZ, 2020). Além disso, para os autores supracitados, diversos colaboradores passam por abusos no ambiente laboral, reforçando ainda mais a importância em se discutir um modelo de sustentabilidade e RH para as organizações.

Com isto, a sustentabilidade e a área de RH representam bem mais do que princípios e atividades filantrópicas ocasionais que não estejam ligados às estratégias organizacionais, como atenta Rezaee (2017). A inclusão da sustentabilidade, por exemplo, é essencial a toda organização que deseja obter sucesso em sua atuação. Dessa forma, como argumentam Kramer e Porter (2006), a área de RH proporciona oportunidades para que a organização possa entender e buscar introduzir a sustentabilidade nas estratégias estipuladas, o entendimento do processo estratégico e identificação do compromisso da sustentabilidade da organização (REN; TANG; JACKSON, 2018).

As áreas, trabalhando de forma conjunta, podem desenvolver estratégias que contribuem para o desenvolvimento sustentável da organização. Assim, o estudo realizado por Parente e Fischer (2015) relata que a área de RH tem um grande desafio voltado à sustentabilidade, evidenciando que a relação pode ser considerada uma temática emergente. Ainda, entendeu-se no estudo que esta relação entre os setores vem crescendo a cada ano e que, tanto nacionalmente quanto internacionalmente, as abordagens do tema só aumentam. Administrar estrategicamente está ligado ao futuro, e, sendo executada de forma consistente, pode fortalecer normas, regras e funções que auxiliam no alcance do processo de planejamento desejado pela empresa. Assim como, organizar e direcionar os recursos empresariais de maneira potencializada com a realidade ambiental e maximizar as relações interpessoais (OLIVEIRA, 2007).

Diante disso, o estudo de Alvares e Souza (2016) sugere que seja realizada uma pesquisa que aborde as contribuições na área de gestão de recursos humanos sustentável, a fim de proporcionar as às empresas um maior entendimento e importância desse tema na sua administração. Nesse contexto, a presente pesquisa abordará a aplicação do método Analytic Hierarchy Process (AHP), sendo que esse vai ao encontro da busca por melhorias e contribui para a resolução de problemas complexos. Assim, tem-se o seguinte problema nesta pesquisa: Quais são os indicadores que os colaboradores e gestores acreditam ser mais importantes para o desenvolvimento da gestão de recursos humanos sustentável?

Este estudo objetiva desenvolver uma modelagem, a fim de elencar os principais indicadores que contribuem para a gestão de recursos humanos sustentáveis, sob a percepção dos colaboradores e gestores de uma multinacional. Para o desenvolvimento dessa pesquisa, utilizaram-se alguns indicadores apresentados no estudo de D'Amorin (2009). Nessa perspectiva, justifica-se a relevância desse estudo, pois ele contribui para o avanço de pesquisas sobre gestão de recursos humanos sustentáveis, acrescentando à literatura nacional estudos teórico-empíricos que contemplem essa temática. Além disso, o estudo investiga o desenvolvimento de estratégias sustentáveis aplicadas na área de gestão de pessoas, podendo, assim, ser adotadas por diversas organizações. 
Análise da gestão de recursos humanos sustentável: um estudo em uma multinacional

\section{GESTÃO DE RECURSOS HUMANOS SUSTENTÁVEL}

Para uma empresa manter-se competitiva no mercado, ela precisa de práticas que excedam as habituais recomendações de melhoria dos processos organizacionais e redução de recursos (FREITAS et al., 2013). Para haver valorização do empreendimento, é necessário desenvolver práticas socioambientais inovadoras que estejam em harmonia às funções organizacionais, com objetivo primário de viabilizar crescimento econômico em longo prazo (SROUFE; COFFINO; CARLSON, 2010).

Para tanto, pesquisadores vêm estudando formas de prosperar nesse sentido, e a Gestão de Recursos Humanos (GRH) é vista como elemento construtivo desse processo, uma vez que as pessoas são tidas como os recursos mais valiosos dentro de uma organização, além de serem consideradas essenciais para o crescimento e competitividade de um negócio ALCARAZ et al., 2017). Nesse sentido, busca-se investir no capital humano como forma de engrandecer o valor do colaborador para a organização. Esse investimento consiste em numa valorização dos funcionários em questões de uma boa remuneração, proporcionar treinamentos, além de investimentos para melhores condições de trabalho (SROUFE; COFFINO; CARLSON, 2010).

A Gestão de Recursos Humanos refere-se a um conjunto de dimensões organizacionais planejadas com objetivo de influenciar o comportamento dos funcionários, auxiliando na obtenção dos objetivos empresariais. Busca-se o alcance desse objetivo, por meio do relacionamento da área de recursos humanos com as demais áreas, aspirando à promoção de vantagens competitivas (JABBOUR; SANTOS; NAGANO, 2009). Freitas et al. (2013), complementam que a GRH é um aglomerado de práticas que buscam o engajamento das pessoas com a estratégia organizacional e que a sustentabilidade se refere ao aporte com o desenvolvimento sustentável que contribui para o fortalecimento dos três pilares da sustentabilidade que são: benefícios econômicos, sociais e ambientais.

Tratando-se do pilar econômico, esse refere-se à profusão de alternativas que atestem viabilidade, competitividade e legitimidade para as empresas em longo prazo. O pilar socialcaracteriza-se por um sistema de trabalho pautado na renovação, regeneração, reprodução dos recursos humanos (D'AMORIM, 2009). Quanto à perspectiva ambiental, ela possui relações com o trabalho e o meio ambiente, que se define como uma coleção de elementos físicos, químicos, biológicos e sociais que podem proporcionar resultados de forma direta ou indireta nos seres vivos e nas atividades humanas (MASCARENHAS; BARBOSA, 2019).

A partir dessa multidisciplinaridade, os profissionais de $\mathrm{RH}$ têm como tarefa auxiliar em questões globais, que dizem respeito a mudanças sociais, tecnológicas, ambientais, políticas, econômicas e demográficas. Rimanoczy e Person (2010) ratificam a ideia de que a GRH é uma força motriz que possibilita mudanças organizacionais e atualização dos valores que moldam a cultura organizacional em busca da sustentabilidade.

Para a GRH ser considerada, deve ter uma política de gestão que esteja focada no que realmente é justo, que possui aprovação pela cultura local que incita a atitudes ecologicamente corretas e acima de tudo que sejam economicamente viáveis. Como forma de sintetizar o conteúdo, elaborou-se o Quadro 1 com base em D'Amorim (2009).

A partir do Quadro 1, define-se que a GRH sustentável consiste em atitudes que sejam eticamente responsáveis que estejam em concordância com pelo menos uma das dimensões da sustentabilidade (econômica, social e ambiental), num cenário interno, como forma de dignificar as estratégias de uma organização. 
Morgana Klesener, Roger da Silva Wegner, Michel Barboza Malheiros, Vanessa Piovesan Rossato e Vania de Fátima Barros Estivalete

Quadro 1 - Princípios da GRH Sustentável

\begin{tabular}{l} 
Princípios \\
\hline $\begin{array}{l}\text { Princípio 1- As ações de RH sustentáveis integram de forma sistêmica as dimensões da } \\
\text { sustentabilidade, considerando sua interferência entre si. }\end{array}$ \\
\hline $\begin{array}{l}\text { Princípio 2- A dimensão econômica nas ações de RH sustentáveis trata de investimentos no capital humano, } \\
\text { visando a seu desenvolvimento e manutenção de sua vantagem competitiva no mercado. }\end{array}$ \\
\hline $\begin{array}{l}\text { Princípio 3- O homem-funcionário é ator social do processo de trabalho e produção dos resultados, devendo } \\
\text { as ações de RH sustentáveis oportunizar sua participação coletiva como atendimento de uma necessidade } \\
\text { humana e à democracia. }\end{array}$ \\
\hline $\begin{array}{l}\text { Princípio 4- O ambiente interno das organizações é o meio no qual ocorrem ações de RH sustentáveis, que } \\
\text { interferem na qualidade de vida e no desempenho dos funcionários. }\end{array}$ \\
\hline $\begin{array}{l}\text { Princípio 5- As ações de RH sustentáveis são desenvolvidas como políticas de RH e ou por } \\
\text { subsistemas de RH, ambos, em consonância com as estratégias da organização }\end{array}$ \\
\hline $\begin{array}{l}\text { Princípio 6- As ações de RH sustentáveis voltam - se para o homem em sua subjetividade, sendo dotadas de } \\
\text { essência humanizada que refletem uma conduta eticamente responsável. }\end{array}$ \\
\hline
\end{tabular}

Fonte: adaptado de D'Amorim (2009).

Como consequência, têm-se melhores condições de trabalho para os funcionários, uma vez que se investe no capital humano e melhorias no desempenho como forma de adquirir vantagens competitivas.

\section{PROCEDIMENTOS METODOLÓGICOS}

Para atender o objetivo, o presente estudo se caracterizou como descritivo, com abordagem quantitativa e qualitativa. $\mathrm{O}$ objeto de estudo foram funcionários e gestores de uma unidade de multinacional localizada no norte do Rio Grande do Sul. A organização estudada produz bebidas e alimentos, conta com mais de 2.000 marcas e está atuando em diversos países do mundo. Atualmente, essa organização é vista como uma das empresas mais sustentáveis do mundo. Essa trabalha em diversos projetos sustentáveis tais como: embalagens sustentáveis, redução de água, resíduos e desperdícios, entre outros. A empresa busca oferecer aos seus funcionários cursos de capacitação voltados à sustentabilidade, além de investir em certificações como a ISO 22000, a ISO 18001 e ISO 14001, e essas abrangem aspectos voltados à segurança de alimentos e gestão ambiental.

Dessa forma, 42 funcionários (38 colaboradores e 4 gestores) participaram da pesquisa. Assim, a amostra foi caracterizada como não-probabilística, bem como por acessibilidade. Em relação à abordagem quantitativa, utilizou-se um questionário, e esse instrumento abordou alguns indicadores utilizados no estudo de D'Amorin (2009). O questionário apresentava 20 indicadores e foi aplicado para todos os participantes da pesquisa. Já na abordagem qualitativa, foram realizadas entrevistas com os 4 gestores (Gestor A -Manutenção; Gestor B - Produção; Gestor C - Recursos humanos; e o Gestor D - Meio ambiente), visando detalhar o grau de importância dado por esses.

Para desenvolver a modelagem dessa pesquisa, foi empregado o método Analytic Hierarchy Process (AHP). O método AHP, sendo aplicado nas organizações, pode contribuir de modo estratégico, pois tem o objetivo de identificar as causas de problemas para fornecer suporte na tomada de decisão para a resolução desses (MIN, 2010). O referido método foi desenvolvido por Thomas L. Saaty, nos anos 1970, e se configura como um método multicritério e alta relevância (SAATY, 2008). O AHP consiste na hierarquização de possíveis causas de problemas, da mesma forma reúne alternativas possíveis para soluções (SAATY; OZDEMIR, 2003; SAATY, 2008).

Conforme explicam Saaty e Shih (2009), primeiramente é realizada uma classificação para elencar o problema principal identificado. Esse se divide em partes, sendo a formação 
primária composta pela estrutura relatada do problema, o qual possui três classes: o objetivo, os critérios e as possíveis soluções para o problema. Partindo disso, realiza-se uma classificação, na intenção de elencar o problema principal (SAATY; SHIH, 2009). Esse se divide em partes, formando uma árvore, sendo o propósito geral a base da estrutura. Na formação primária, a estrutura relata o problema, possuindo três classes: sendo a primeira, o objetivo, a segunda, os critérios e a terceira, os subcritérios.

Por meio do uso da Escala de Saaty e Shih (2009), é realizado o julgamento de comparação, no qual os termos verbais são transformados em valores numéricos, como se pode analisar na Tabela 1.

Tabela 1 - Escala de importância

\begin{tabular}{ccc}
\hline Escala & Avaliação & Recíproco \\
Extremamente preferido & 9 & $1 / 9$ \\
Muito forte a extremo & 8 & $1 / 8$ \\
Muito fortemente preferido & 7 & $1 / 7$ \\
Forte a muito forte & 6 & $1 / 6$ \\
Fortemente preferido & 5 & $1 / 5$ \\
Moderado a forte & 4 & $1 / 4$ \\
Moderadamente preferido & 3 & $1 / 3$ \\
Igual a moderado & 2 & $1 / 2$ \\
\hline
\end{tabular}

Fonte: Saaty e Shih (2009).

Para analisar a consistência do julgamento, se faz o uso de dados brutos de uma determinada base e demais dados que podem ser deduzidos de forma lógica. Os valores podem se mostrar inconsistentes, para isso, Saaty (2004) desenvolve procedimentos a fim de avaliar a consistência dos julgamentos: o Índice de Consistência (IC - Consistency Indexou) e a Razão de Consistência (RC - ConsistencyRatio). O IC avalia o grau de inconsistência da matriz realizada par a par. Esse índice é calculado com o emprego do $\lambda_{\max }$, alcançado por: $\mathrm{IC}=\left(\lambda_{\max }-\right.$ n)/(n-1).

Na sequência, utiliza-se o cálculo da razão de consistência (RC), esse se advém aplicando-se: $C R=I C / I R$. Com isso, o índice randômico (IR) é alcançado por simulação e é sintetizado na Tabela 2. Na maioria das vezes, uma consistência que se pode aceitar para $n>$ 4 é quando $\mathrm{RC} \leq 0,10$ (SAATY, 2008). Identificado como o índice de consistência obtido para uma matriz randômica recíproca, o Índice Randômico apresentando elementos não negativos, para variados tamanhos de matriz. Na Tabela 2 pode ser visualizado.

Tabela 2 - Índice de Consistência Randômica

\begin{tabular}{c|c|c|c|c|c|c|c|c|c|c|c|c|c}
$\begin{array}{c}\text { Ordem da } \\
\text { Matriz }\end{array}$ & $\mathbf{1}$ & $\mathbf{2}$ & $\mathbf{3}$ & $\mathbf{4}$ & $\mathbf{5}$ & $\mathbf{6}$ & $\mathbf{7}$ & $\mathbf{8}$ & $\mathbf{9}$ & $\mathbf{1 0}$ & $\mathbf{1 1}$ & $\mathbf{1 2}$ & 13 \\
\hline Valores do IR & 0 & 0 & 0,58 & 0,90 & 1,12 & 1,24 & 1,32 & 1,14 & 1,45 & 1,49 & 1,51 & 1,48 & 1,56 \\
\hline
\end{tabular}

Fonte: adaptado de Saaty (2004).

Para que uma matriz seja considerável, é necessário ter um IR com uma razão de consistência menor ou igual a 0,10 (SAATY, 2004). Os passos utilizados na aplicação do método no presente estudo são detalhados nos próximos parágrafos. O cálculo do peso local será descrito nos próximos parágrafos. Partindo disso, o primeiro passo foi criar a estrutura hierárquica da modelagem, conforme apresentado na Figura 1. Nessa etapa, foi definido o objetivo geral que compõe a ideia de elencar as principais variáveis que contribuem para a gestão de recursos humanos sustentável, sob a percepção dos colaboradores e gestores de uma multinacional, baseado nos indicadores apresentados no estudo de D’Amorin (2009). 
Morgana Klesener, Roger da Silva Wegner, Michel Barboza Malheiros, Vanessa Piovesan Rossato e Vania de Fátima Barros Estivalete

Figura 1 - Árvore Hierárquica da modelagem proposta

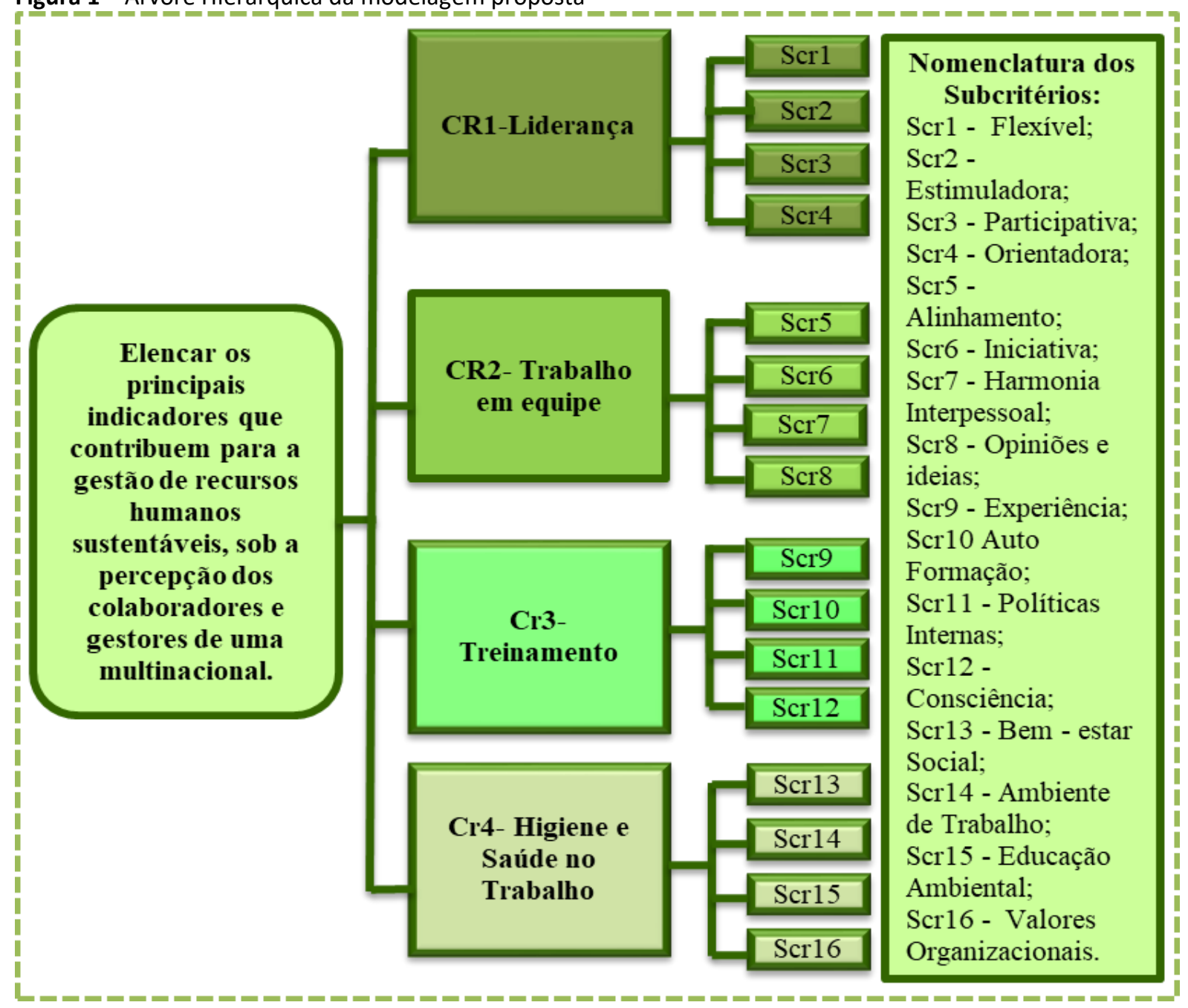

Fonte: dados da Pesquisa (2018).

$\mathrm{Na}$ sequência, foram desenvolvidas matrizes com os critérios e subcritérios. Em seguida, por meio da combinação binária, analisou-se o nível de cada variável, usando a escala de importância de Saaty, conforme apresentado na Tabela 1, empregando os pesos 3, 5, 7, 9, que significam a ordem de maior importância para comparação par a par, os pesos 2, 4, 6, 8, que são os valores intermediários e 1 que simboliza a igualdade na importância. Sendo assim, foi possível realizar a comparação par a par dos critérios e subcritérios e, então, construir as matrizes com o julgamento dos colaboradores e gestores.

Para finalizar a análise, faz-se um julgamento do vetor de prioridade, sendo possível verificar a hierarquia dos critérios e subcritérios e sua veracidade. Para o índice de Consistência Randômica das matrizes, foi utilizado o valor de 0,90 , devido à matriz ser de $4 \times 4$, atendo um percentual de erro de até $10 \%$. Após a realização dos procedimentos citados, se encontrou o peso local (PL) dos critérios e subcritérios. Partindo disso, realizou-se o cálculo do peso global (PG) para cada subcritério, adotando a fórmula: PG (Scr1) = PL (Cr1) * PL (Scr1) / 100; PG (Scr2) = PL (Cr1) * PL (Scr2) /100; PG (Scr3) = PL (Cr1) * PL (Scr3) /100; PG (Scr4) = PL $(\mathrm{Cr} 1)$ * PL (Scr4) /100; PG (Scr1) = PL (Cr2) * PL (Scr1) /100, e assim sucessivamente.

Empregou-se essa fórmula e se obteve o peso global (PG) de todos os subcritérios. Os resultados foram expostos na forma de gráficos. Assim, por meio dessa modelagem desenvolvida, foi possível compreender as prioridades das variáveis estudadas. Salienta-se que os dados apresentados foram analisados no software Microsoft ExcelC. 
Análise da gestão de recursos humanos sustentável: um estudo em uma multinacional

\section{ANÁLISE DOS RESULTADOS}

\subsection{JULGAMENTO REALIZADO SOB A PERCEPÇÃO DOS COLABORADORES}

O primeiro grupo pesquisado engloba todos os colaboradores, tanto os que exercem atividades administrativas como operacionais. Funcionários responsáveis por compras de insumos, programações, manutenção, compras diversas, recepção e processamento da matéria-prima, segurança, meio ambiente e qualidade. Na Figura 2, visualiza-se o julgamento do peso global dos critérios e o peso local dos subcritérios, sob a percepção dos colaboradores. Essa modelagem ajudou a identificar - as ações que contribuem para a gestão de recursos humanos sustentável, sob a visão desses participantes.

Figura 2 - Peso global dos critérios e peso local dos subcritérios sob a percepção dos colaboradores

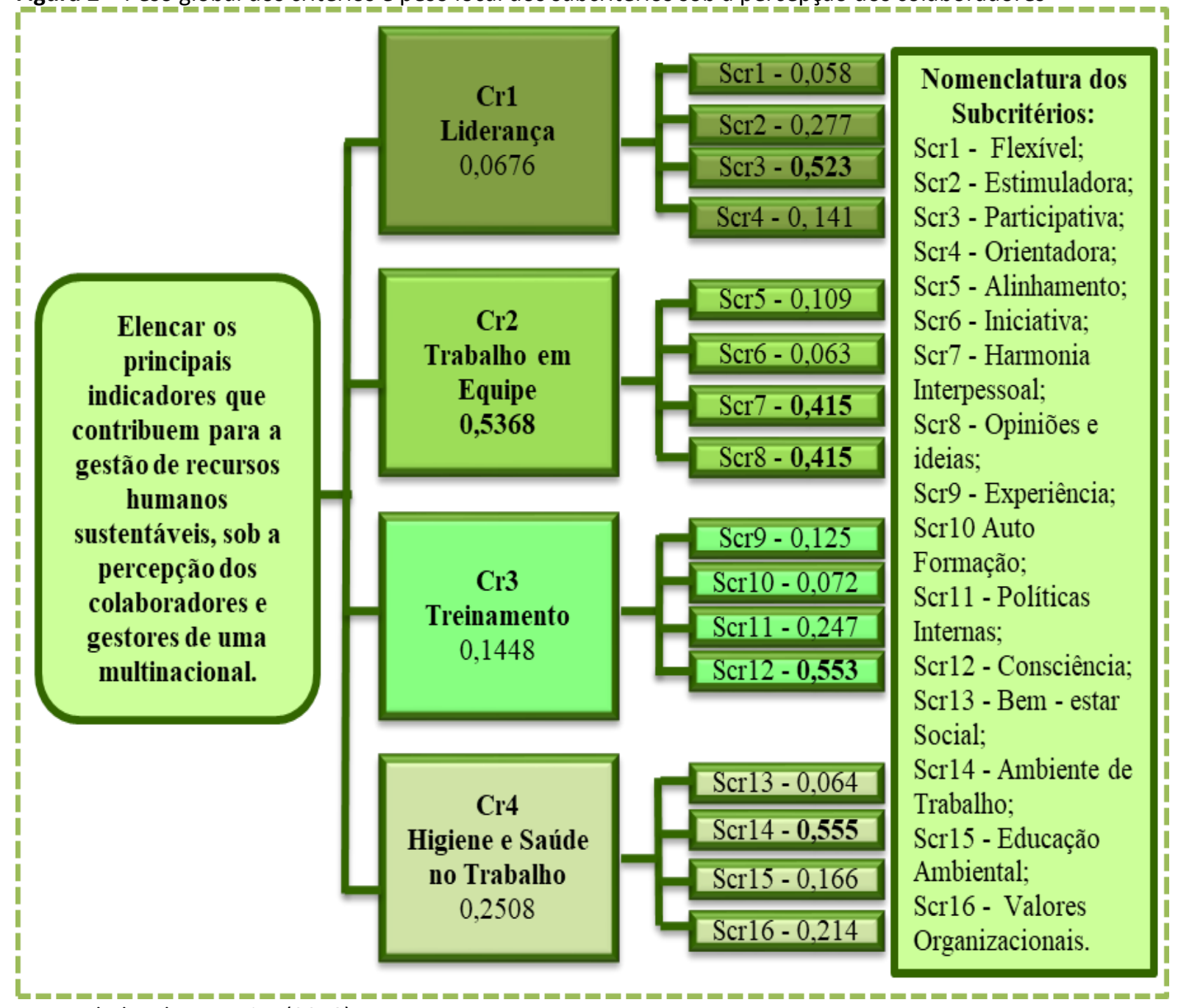

Fonte: dados da Pesquisa (2018).

Conforme os dados apresentados, percebe-se que o " $\mathrm{Cr} 2$ - Trabalho em equipe" foi evidenciado como o mais importante para a gestão sustentável de recursos humanos. De acordo com Housel (2008), uma equipe pode alcançar resultados impactantes com ações de pequena escala, se souber utilizar seu poder de forma correta. O destaque do "Cr2" em relação aos demais critérios foi de 0,5368. Dentro desse critério, os subcritérios que tiveram maior importância foram os "Scr7 - Harmonia interpessoal" e "Scr8 - Opiniões e ideias", ambos com peso de $(0,415)$. Os trabalhadores apresentam ideias diferentes, mas, no contexto 
Morgana Klesener, Roger da Silva Wegner, Michel Barboza Malheiros, Vanessa Piovesan Rossato e Vania de Fátima Barros Estivalete

organizacional, os objetivos estabelecidos pela organização alinham - se às diferentes opiniões da equipe (HARDINGHAM, 2000).

Os colaboradores classificam como segunda maior importância o " $\mathrm{Cr} 4$ - Higiene e Saúde no trabalho", com 0,2508. Nesse, encontra-se o subcritério que teve maior importância entre todos, sendo ele o "Scr14 - Ambiente de trabalho", com peso $(0,5554)$. O terceiro mais importante ficou o "Cr3 - Treinamento" com 0,1448, sendo o "Scr12 - Consciência" o de maior peso $(0,5538)$ dentro desse critério. Com menor grau de importância para os colaboradores, o "Cr1 - Liderança", que recebe 0,0676, e com peso (0,5232), o "Scr3 - Participativa" destacase como mais importante entre os subcritérios do "Cr1".

A Figura 3 apresenta o peso global dos subcritérios julgados sob a percepção dos colaboradores. Na classificação de prioridades, os subcritérios "Scr7 - Harmonia Interpessoal" e "Scr8 - Opiniões e Ideias" que se encontram no "Cr2 - Trabalho em equipe", têm maior importância entre todos os outros subcritérios. E o que menor importância recebe é "Scr1 Flexível" ficando na última posição, estando no "Cr1 - Liderança".

Figura 3 - Peso global dos subcritérios sob a percepção dos colaboradores

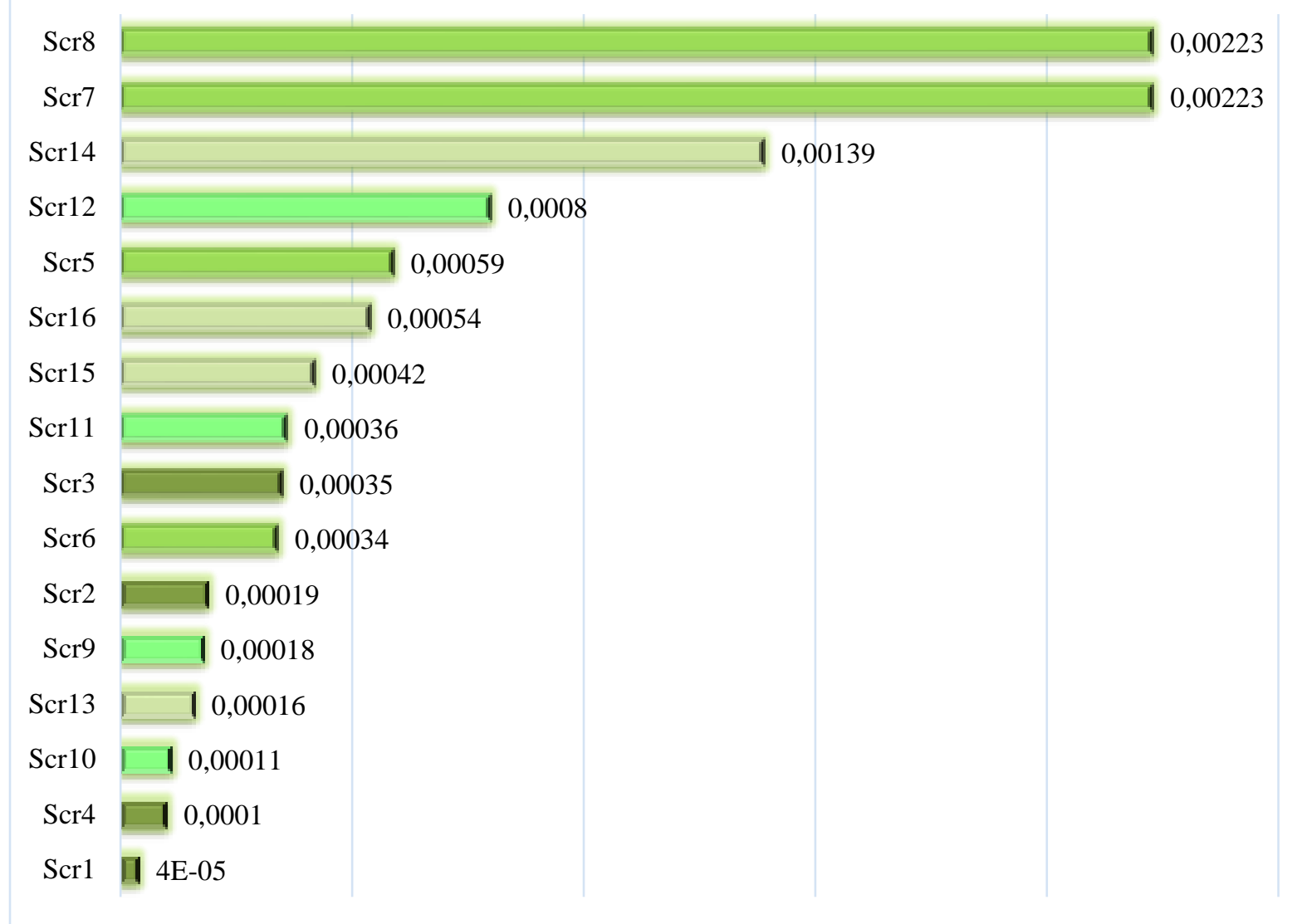

Fonte: dados da Pesquisa (2018).

Na perspectiva dos colaboradores, o trabalho em equipe tem maior importância para o desenvolvimento sustentável da empresa, considerando a harmonia entre colegas um ponto bastante relevante. Diante das análises realizadas, procura-se encontrar resultados coerentes para as matrizes. Podendo ser visualizados na Figura 4, que demonstra o índice de consistência. 
Análise da gestão de recursos humanos sustentável: um estudo em uma multinacional

Figura 4 - Índice de consistência da matriz julgada pelos Colaboradores

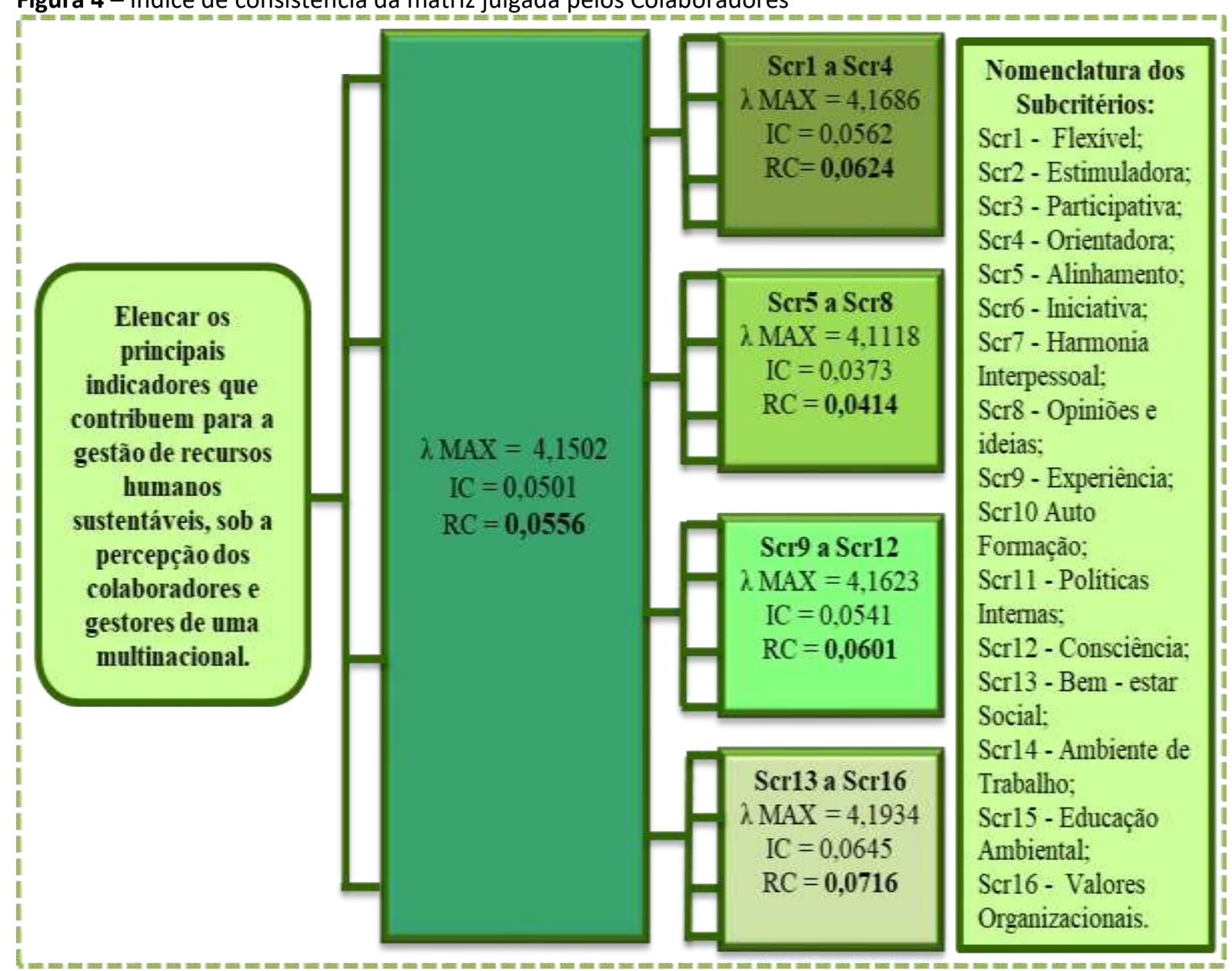

Fonte: dados da Pesquisa (2018).

Para Saaty (2004), para que o julgamento da matriz esteja coerente, o RC deve ser menor ou igual a 0,10. Como se pode perceber, todos os julgamentos demonstram coerência devido a estarem dentro do percentual permitido. Na próxima subseção, será apresentado o julgamento do Gestor A.

\subsection{JULGAMENTO REALIZADO SOB A PERCEPÇÃO DO GESTOR A - MANUTENÇÃO}

O Gestor de manutenção da empresa investigada é responsável por uma equipe composta por analista, estagiário, mecânicos, eletricista e operadores de utilidades, as quais atuam na unidade e diretamente com os colaboradores. Além disso, se responsabiliza por todo o funcionamento dos equipamentos e máquinas ligadas à área de produção, como também garantir pleno funcionamento da estação de tratamento de água, também responsável pelo estoque de peças e outros produtos que devem ter armazenamento controlado. Diante disso, na Figura 5, é possível visualizar o julgamento do Gestor A, apresentando o peso global dos critérios e o peso local dos subcritérios. 
Morgana Klesener, Roger da Silva Wegner, Michel Barboza Malheiros, Vanessa Piovesan Rossato e Vania de Fátima Barros Estivalete

Figura 5 - Peso global dos critérios e peso local dos subcritérios sob a percepção do Gestor A.

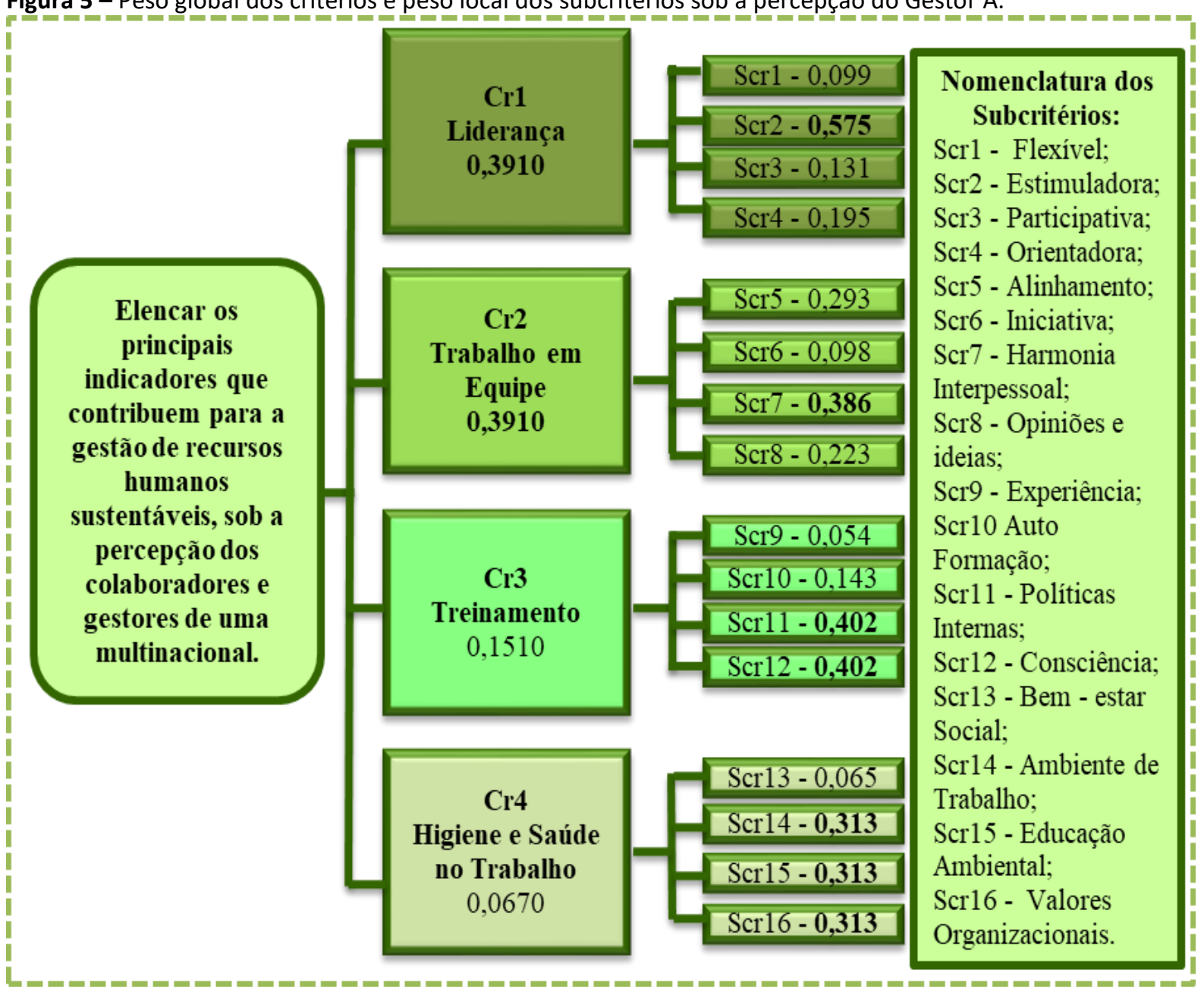

Fonte: dados da Pesquisa (2018).

De acordo com a tabela, o Gestor A julgou importante o "Cr1 - Liderança" e "Cr2 Trabalho em equipe", e o valor atingido pelos dois critérios foi de 0,3910. Para Gracioso (2009), o trabalho em equipe melhora o desempenho individual e organizacional, pois os integrantes dela entendem os objetivos da empresa e envolvem-se para atingi-los. O autor ainda destaca que compete ao líder a tarefa de conduzir pessoas e equipe diante das agitações causadas pelas mudanças organizacionais, fazendo com que as dificuldades sejam superadas e novos contextos entendidos.

Quando conversado com o Gestor A ele explica por que acredita que a liderança é importante para o desenvolvimento sustentável da empresa dizendo: “[...] cabe ao líder puxar o assunto sustentabilidade para com os colaboradores, de maneira que eles entendam a importância que isso tem para o crescimento da companhia como um todo".

Na segunda colocação, com maior importância, ficou o "Cr3 - Treinamento" com peso de 0,1509, e os subcritérios que mais se destacam são o "Sr11 - Políticas internas" e "Sr12 Consciência", com peso de $(0,4018)$. E, com o menor peso de importância, destaca-se o "Cr4 - Higiene e saúde no trabalho", com valor de 0,0675. Na Figura 6, é possível analisar o peso global dos subcritérios julgados pelo Gestor $A$. 
Figura 6 - Peso global dos subcritérios sob a percepção do Gestor A

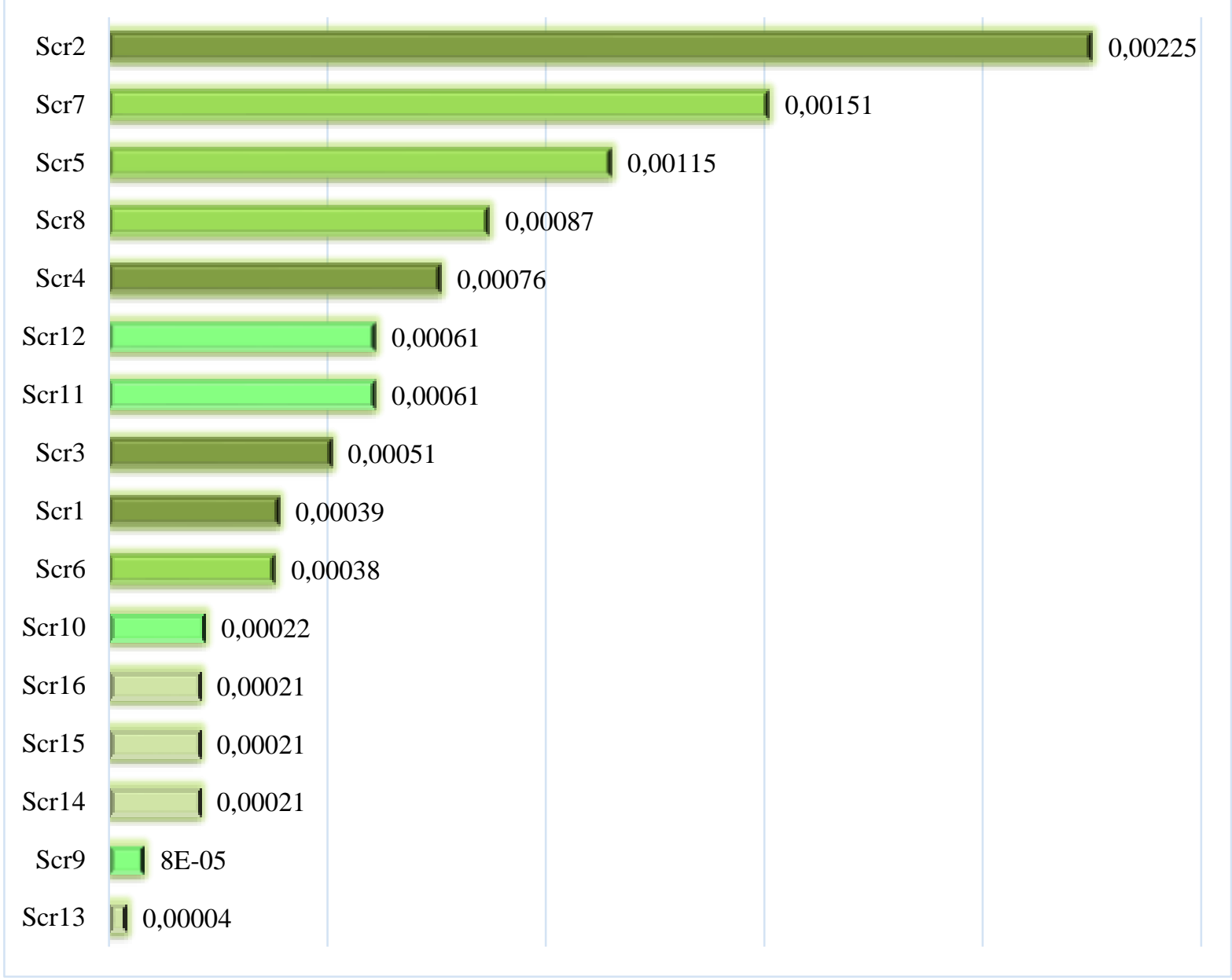

Fonte: dados da pesquisa (2018).

Para os subcritérios, com peso global (0,00225), destaca-se o "Scr2 - Estimuladora" como mais importante, e se encontra no "Cr1 - Liderança". O Gestor A comenta um pouco sobre liderança estimuladora, dizendo: "Como líderes, devemos estimular as pessoas a atingir seu melhor potencial. Isso fará com que a pessoa tenha maior conhecimento, maior domínio na área em que atua e, consequentemente, ela começa a fazer suas atividades com mais segurança e em menor tempo, sobrando mais tempo para que desenvolva outros projetos em paralelo e venha agregar mais conhecimento". Para Lacombe (2011), o líder deve, além de transmitir, criar uma visão de onde deseja chegar, o autor também descreve que essa não deve ser apenas uma iniciativa do líder, mas também de seus seguidores. Em contrapartida, o Scr13 foi o menos priorizado, esse se refere à ideia do bem-estar social. Na Figura 7, apresentam-se os índices de consistência dos julgamentos realizados pelo Gestor A.

Conforme os dados apresentados, percebeu-se que todos os julgamentos estão de acordo com o RC permitido, pois estão apresentando valores menores que 0,10 . Na próxima subseção, será apresentado o julgamento do Gestor B. 
Morgana Klesener, Roger da Silva Wegner, Michel Barboza Malheiros, Vanessa Piovesan Rossato e Vania de Fátima Barros Estivalete

Figura 7 - Índice de consistência da matriz Gestor A

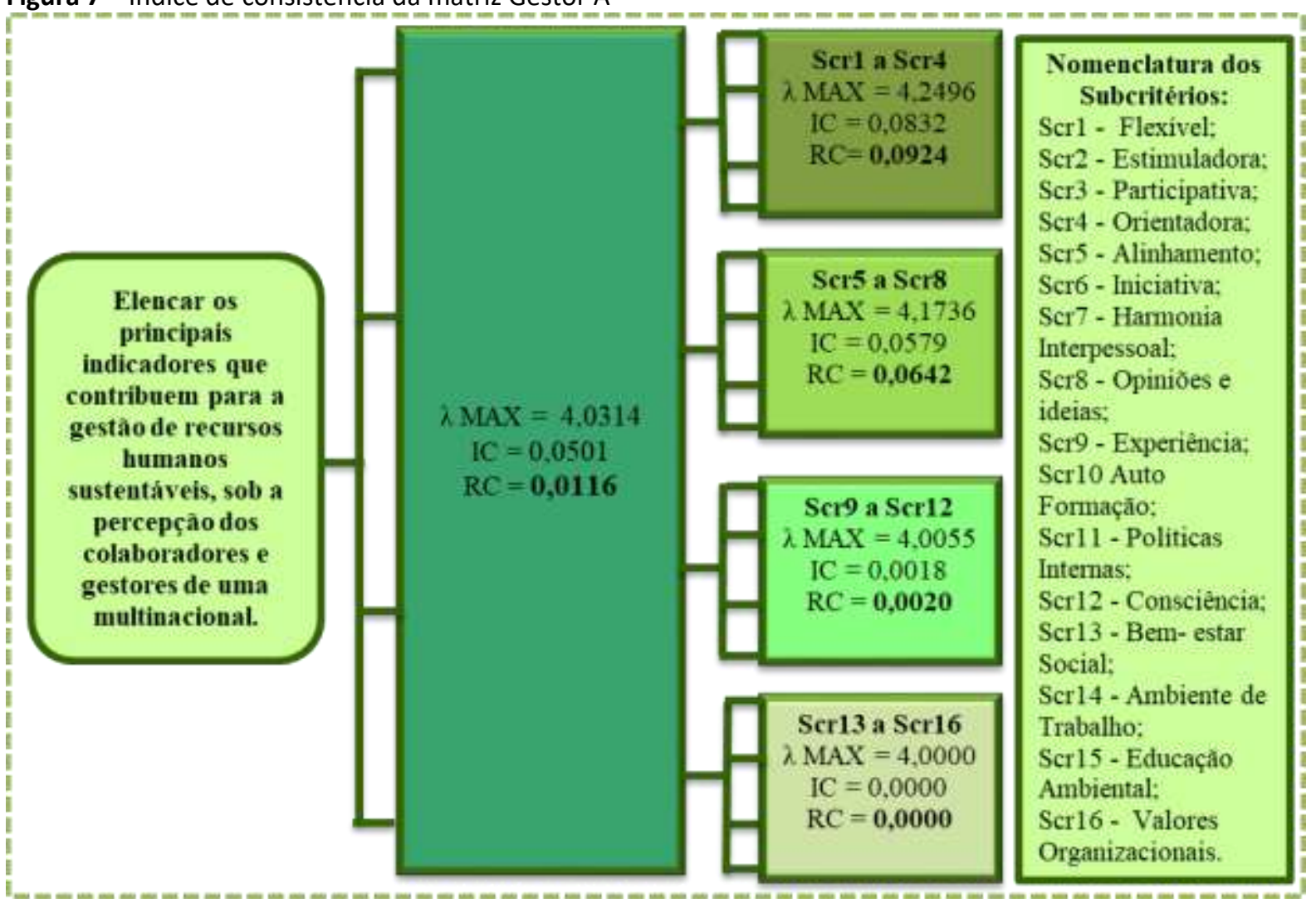

Fonte: dados da Pesquisa (2018).

\subsection{JULGAMENTO REALIZADO SOB A PERCEPÇÃO DO GESTOR B - PRODUÇÃO}

O Gestor de produção é responsável pelos colaboradores da recepção, área fabril e logística do produto final. Esse trabalha na unidade e tem contato direto com seus colaboradores. Estas áreas são responsáveis pelo recebimento da matéria-prima, o processamento dessa e a destinação do produto final. Além disso, a área também é a grande responsável pela qualidade do produto, porque, nas etapas de recebimento processamento e expedição do produto, são realizadas diversas análises, para evitar contaminações.

Na Figura 8, é apresentado o julgamento do Gestor B, destacando o peso global dos critérios e o peso local dos subcritérios. Nessa análise, percebe-se que o critério com maior importância para o Gestor B é o "Cr1 - Liderança”, sendo o valor atingido de 0,5205. Para esse critério, o Gestor B acredita que:

[...] se a empresa tem como valor a sustentabilidade, ela deve fomentar seus líderes para que tenham o mesmo tipo de valor [...]. Se não tem uma liderança que acredite na causa, ela não consegue cascatear para o resto do pessoal [...]. Se a empresa tem um objetivo focado ou voltado para sustentabilidade, o primeiro público que eles têm que atingir é a questão da liderança.

O líder deve possuir a capacidade de ser flexível quanto ao estilo de gestão, para que possa entender a situação e colocar em prática o estilo que mais estiver de acordo com o momento e ambiente (CURY, 2007).

Como se pode perceber, para o Gestor B, os "Cr2 - Trabalho em equipe" e "Cr3 Treinamento" possuem a mesma importância, atingindo um valor de 0,2010 para os dois critérios. Com um peso de 0,0760 , fica como o menos importante entre os quatros critérios o "Cr4 - Higiene e saúde no trabalho". 
Análise da gestão de recursos humanos sustentável: um estudo em uma multinacional

Figura 8 - Peso global dos critérios e peso local dos subcritérios sob a percepção do Gestor B

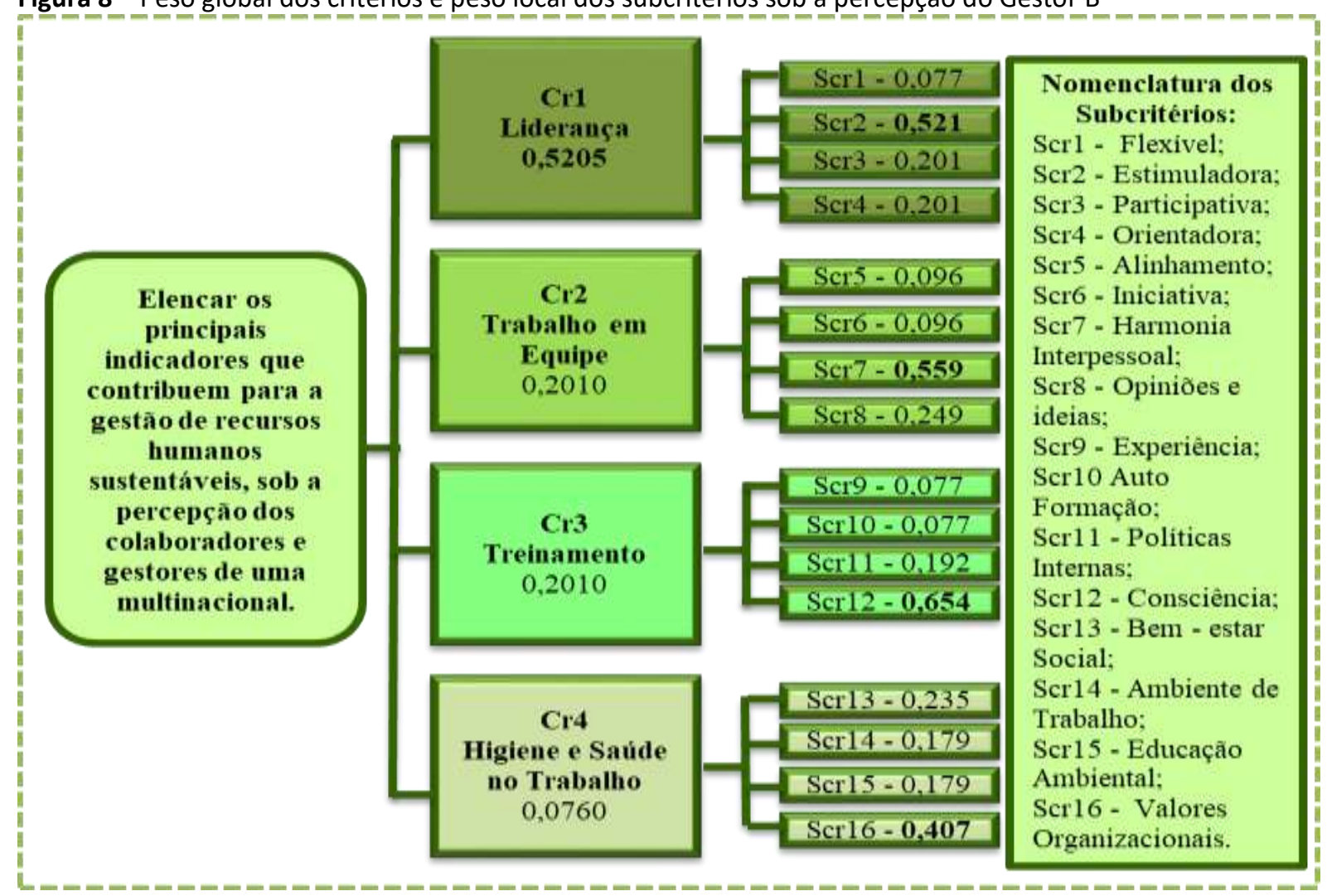

Fonte: dados da pesquisa (2018).

Na Figura 9, é possível analisar o peso global dos subcritérios julgados pelo Gestor B.

Figura 9 - Peso global dos subcritérios sob a percepção do Gestor B

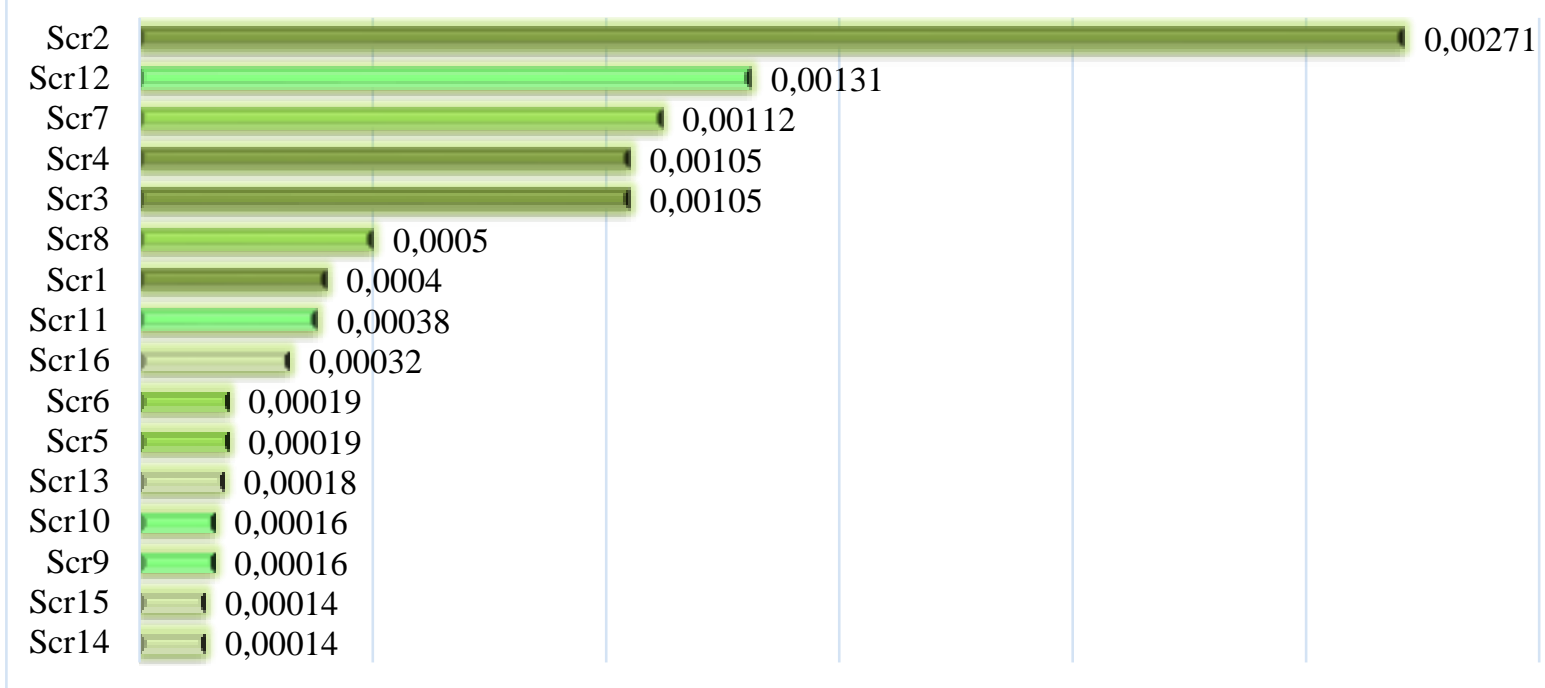

Fonte: dados da pesquisa (2018).

$\mathrm{Na}$ classificação global de prioridades dos subcritérios, percebeu-se que o "Scr2 Estimuladora", com peso (0,00271), foi o que obteve maior grau de prioridade, e esse está dentro do "Cr1 - Liderança". Diante disso, o Gestor B destaca que:

[...] trabalho em equipe, liderança, treinamento, tudo isso é importante, mas, para iniciar a questão da sustentabilidade, você tem que ter um estímulo, ou é no momento que você precisa fazer algo ou pela forma que a companhia tem, em forma de metas, porque às vezes a gente não vê o quanto isso é benéfico [...]. 
Morgana Klesener, Roger da Silva Wegner, Michel Barboza Malheiros, Vanessa Piovesan Rossato e Vania de Fátima Barros Estivalete

Para Robbins (2005), liderar está ligado ao ato de encarar mudanças, e são os líderes que tem o dever de direcionar seus colaboradores, para que possam superar obstáculos e trabalhar em um ambiente motivado ao alcance de objetivos e metas. O líder presente no ambiente organizacional assume a responsabilidade pela administração de recursos humanos, garantindo que a empresa e a sua equipe se sintam apoiadas. Sobre essa realidade, o líder deve desenvolver uma comunicação constante com a sua equipe, apresentando segurança e empatia sobre as tarefas a serem executadas. Além disso, devem estimular a criatividade e a competências dos profissionais, pois as ações criativas desenvolvidas no ambiente laboral podem trazer grandes ganhos para todos os envolvidos.

O segundo subcritério com maior destaque foi o "Sr12 - Consciência", atingindo o peso de $(0,00131)$, localizado no "Cr4 - Treinamento". Para esse subcritério o Gestor B comenta: "[...] se você vai treinar, você consegue desenvolver, então vou colocar consciência como maior [...]. Não importa o que ele traga, vai de um trabalho de engajar, treinar essa pessoa e fazer com que ela tenha consciência, e aí você consegue levar ela para um outro nível [...]". Em contrapartida, o Scr14 "Ambiente de trabalho" obteve o menor grau de prioridade por esse Gestor. Para cada matriz analisada, procura-se a coerência dos resultados encontrados.

De acordo com Freitas et al. (2013, p. 12), "as empresas necessitam de práticas sustentáveis que vão além dos tradicionais conceitos, promovendo a melhoria dos processos organizacionais para a redução dos recursos naturais e resíduos". As práticas da gestão de recursos humanos verde tendem a promover desenvolvimento econômico da organização. Perante cada resultado encontrado na Figura 10, pode ser visualizado o índice de consistência desse julgamento.

De acordo com dados apresentados, os julgamentos realizados para os critérios e subcritérios foram menores que 0,10 , assim demonstrando consistência nos julgamentos realizados. Na próxima subseção, será explanado o julgamento do Gestor C.

Figura 10 - Índice de consistência da matriz Gestor B

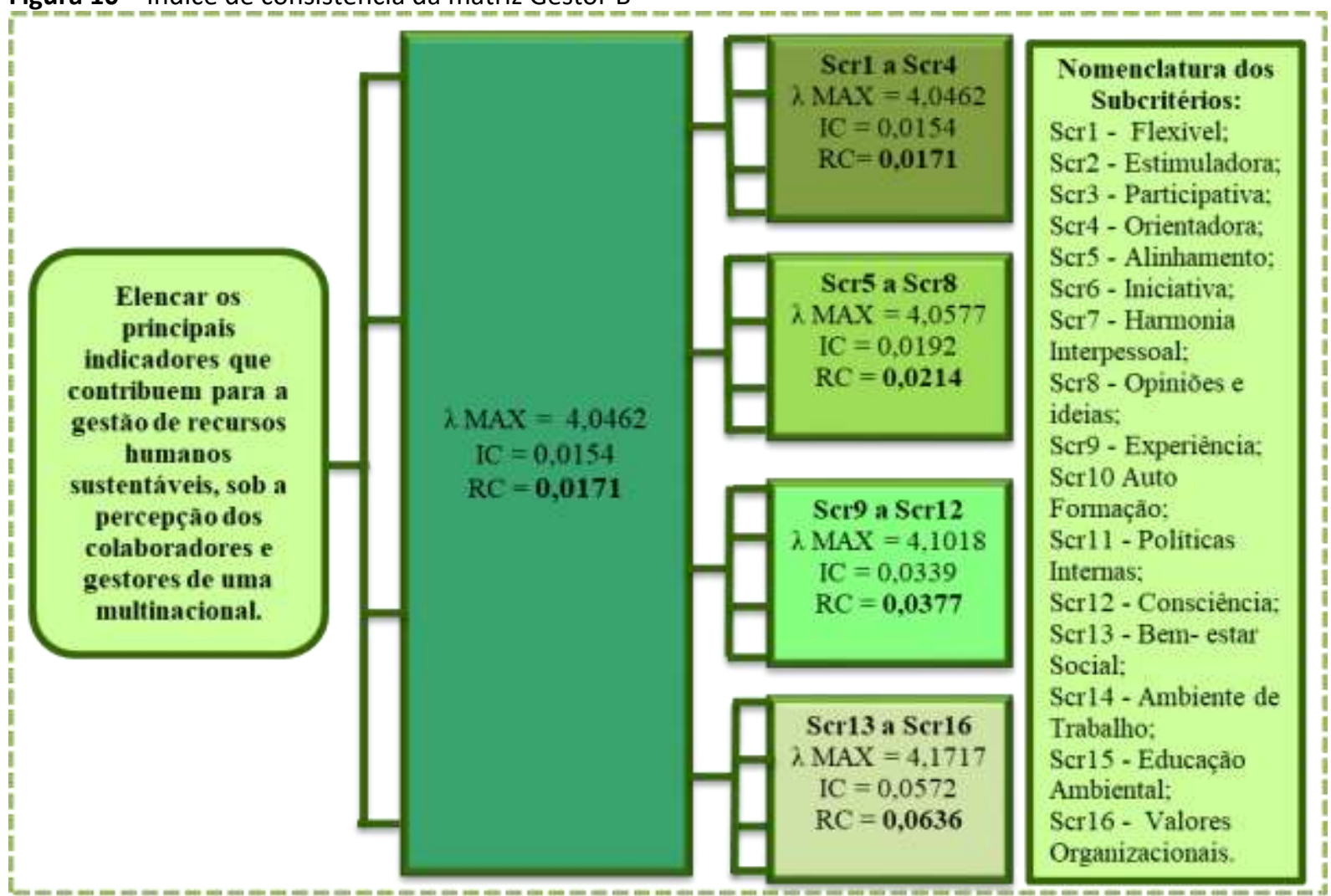

Fonte: dados da pesquisa (2018). 


\subsection{JULGAMENTO REALIZADO SOB A PERCEPÇÃO DO GESTOR C - RECURSOS HUMANOS}

A área de Recursos Humanos é composta pelo Gestor, um estagiário e um menor aprendiz. Esta área atua com responsabilidade voltada diretamente ao colaborador, auxiliando os demais gestores no desempenho de suas funções e formação dos demais colaboradores. Tem a função de garantir que os direitos e deveres sejam cumpridos pelas partes envolvidas, assim como auxiliar no engajamento e desenvolvimento de todos. Assim, na Figura 11, é apresentado o julgamento do Gestor C, destacando o peso global dos critérios e o peso local dos subcritérios.

Figura 11 - Peso global dos critérios e peso local dos subcritérios sob a percepção do Gestor C

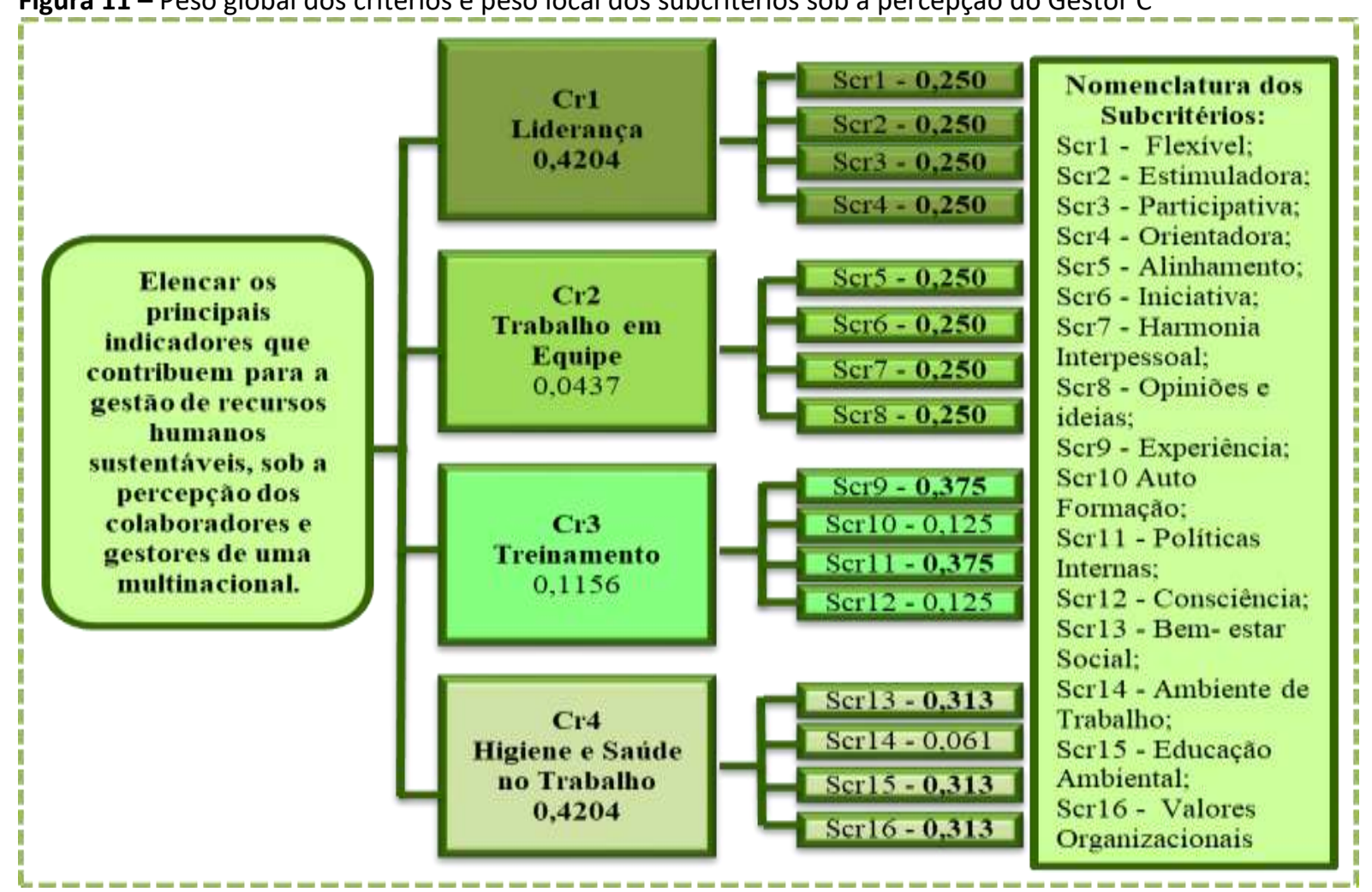

Fonte: dados da pesquisa (2018).

Percebe-se que, para o Gestor C, os critérios mais importantes são os "Cr1 - Liderança" e "Cr4 - Higiene e Saúde no trabalho", com peso de 0,4204. Para Barbieri (2016), engajar colaboradores na inovação e no trabalho, fazendo com que todos se habituem com os resultados causados pela mudança e estejam preparados para tomar ações, é tarefa de um líder. O autor ainda complementa, descrevendo que a liderança é usar a palavra "nós", como se fosse um trabalho em equipe. Com relação à Higiene e Saúde no trabalho, Marras (2016) explica que se trata de uma área que cuida direta e indiretamente da saúde dos colaboradores e está ligada à obtenção de alguma doença referente ao trabalho ou afins.

Para o Gestor C, o "Cr1 - Liderança" tem importância devido a: "Toda empresa independente do ramo precisa ter bons líderes para conduzir as equipes de forma a atingir os objetivos para a empresa ser sustentável e ser competitiva também, então as pessoas sempre se guiam por um exemplo e esse deve ser o melhor possível". Quanto ao "Cr4 - Higiene e Saúde no trabalho, o Gestor relata: "Higiene e saúde no trabalho vêm de encontro com as nossas políticas, que é para a gente conduzir e produzir alimentos seguros, se a gente não tem uma boa condição de saúde, não vamos poder trabalhar adequadamente". 
Morgana Klesener, Roger da Silva Wegner, Michel Barboza Malheiros, Vanessa Piovesan Rossato e Vania de Fátima Barros Estivalete

O terceiro critério mais importante foi o " $\mathrm{Cr} 3$ - Treinamento", com peso de 0,1156, sendo que neste critério os subcritérios "Sr9" e "Sr11" obtiveram maior destaque entre os demais no peso local. E como menos importante o Gestor C classifica o "Cr2 - Trabalho em equipe", com peso de 0,0437. Na Figura 12, é possível analisar o peso global dos subcritérios julgados pelo Gestor C.

Figura 12 - Peso global dos subcritérios sob a percepção do Gestor C

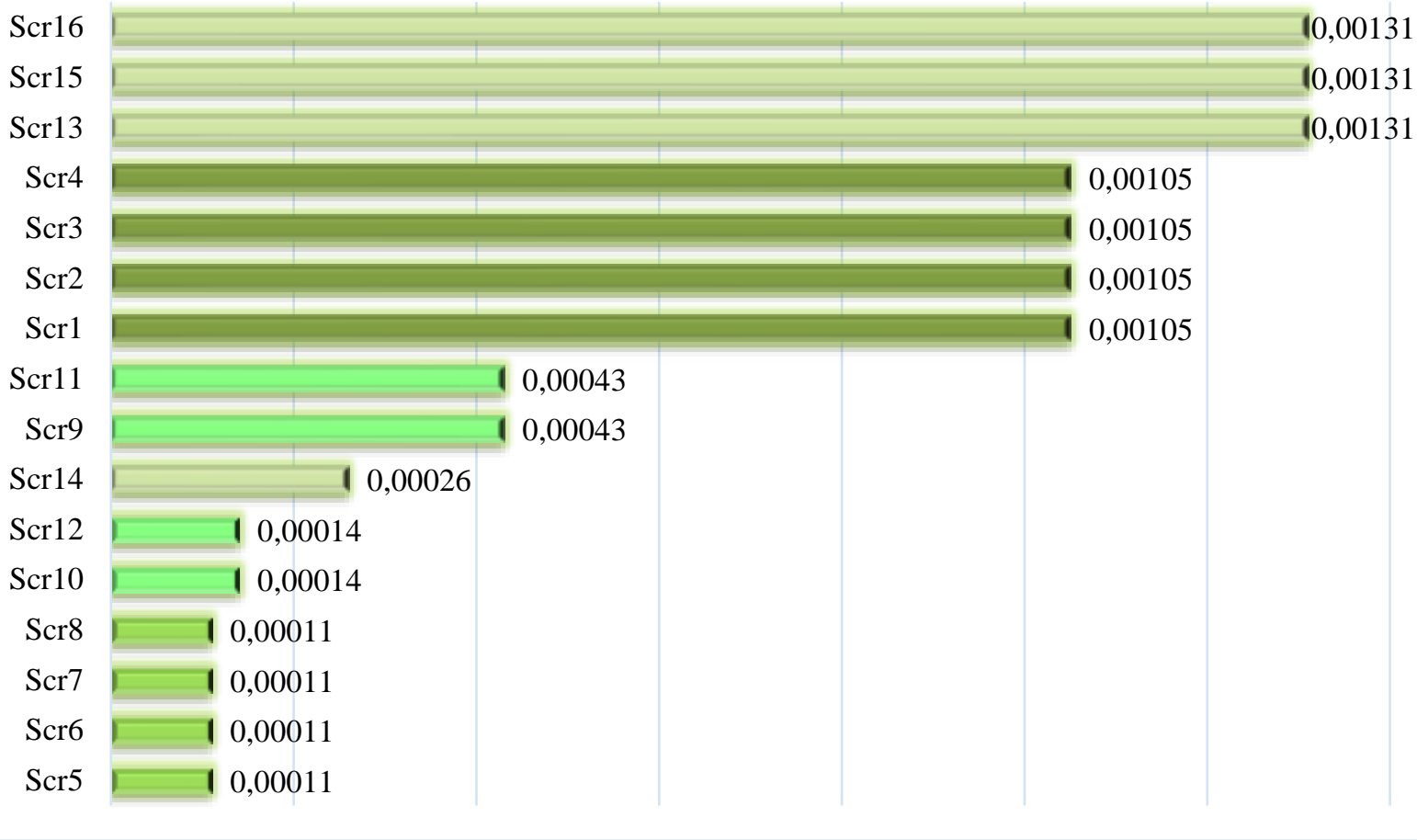

Fonte: dados da pesquisa (2018).

Para a classificação do peso global dos subcritérios analisados, notou-se que o Gestor destacou como o mais importante o "Scr13 - Bem-estar Social", "Scr15 - Educação Ambiental" e "Scr16 - Valores organizacionais", com peso de $(0,00131)$. Todos os três encontram-se no "Cr4 - Higiene e saúde no trabalho". Para Barsano e Barbosa (2014), a higiene industrial é um importante contribuinte para a qualidade de vida no trabalho, pois é através dela que se pode garantir que os colaboradores estarão em um ambiente saudável e sua integridade física e mental será preservada. Com relação a esse subcritério, o Gestor C relata:

toda empresa tem que estar preocupada em ver como está a comunidade em que ela está inserida, se ela está causando benefícios, malefícios ou se está neutra [...]. Como os colaboradores podem aplicar a parte de políticas e valores organizacionais relacionados à sustentabilidade dentro da unidade e também levar isso para sua casa, compartilhar com filhos, seus vizinhos, então tudo que aprendemos aqui dentro a gente pode aplicar lá fora e ser um multiplicador.

Para cada matriz analisada, procura-se a coerência dos resultados encontrados. Perante cada resultado encontrado, na Figura 13, pode ser visualizado o índice de consistência. 
Figura 13 - Índice de consistência da matriz Gestor C

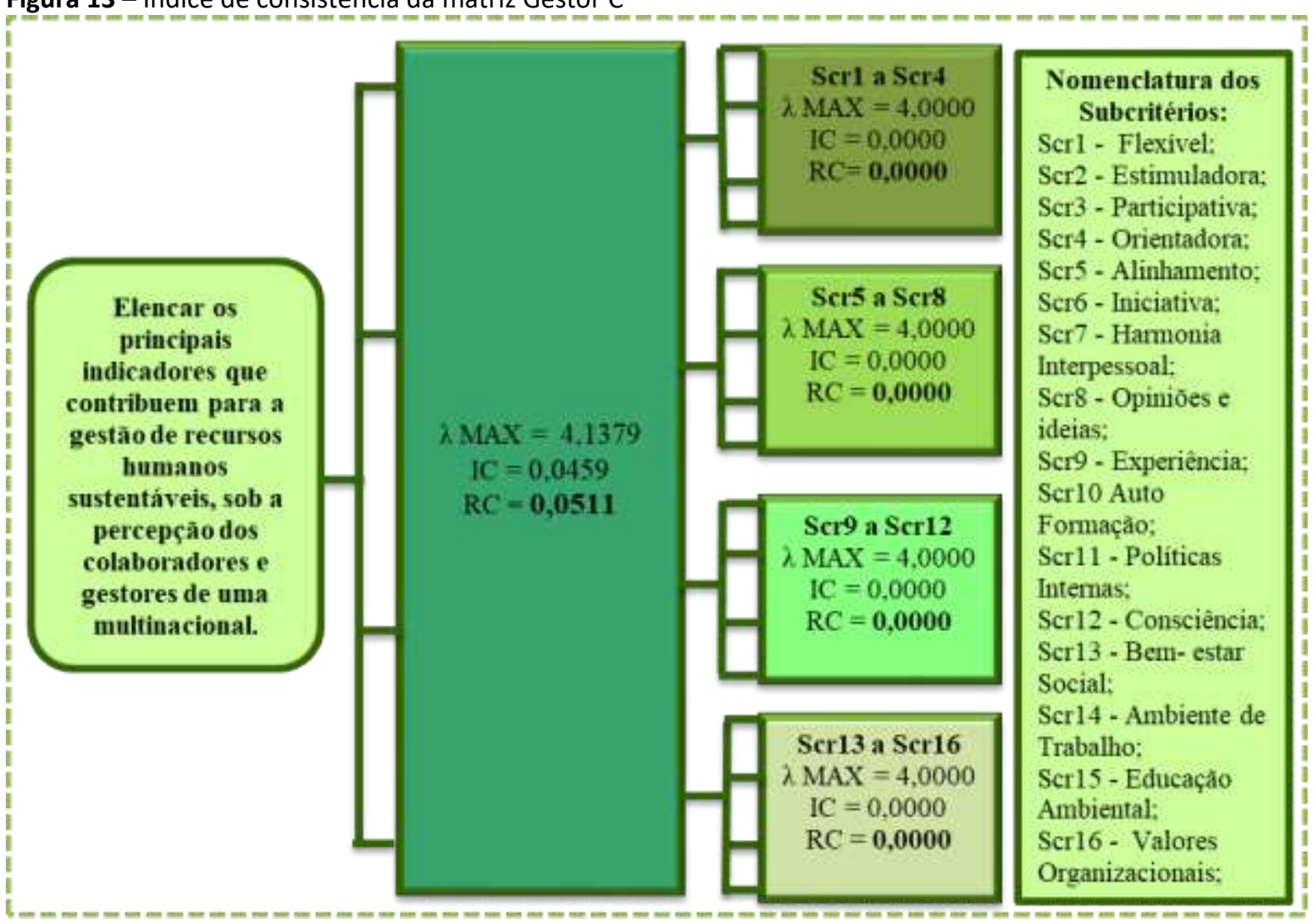

Fonte: dados da pesquisa (2018).

Diante dos resultados obtidos, pode ser observado que os julgamentos realizados foram menores que 0,10 , o que mostra consistência na análise realizada. Na próxima subseção, será exposto o julgamento realizado pelo Gestor D.

\subsection{JULGAMENTO REALIZADO SOB A PERCEPÇÃO DO GESTOR D - MEIO AMBIENTE E PRIORIDADES SIMILARES}

O Gestor de meio ambiente e segurança, que é responsável por um técnico de segurança e estagiário, não atua na unidade, exercendo suas funções e tarefas de outra unidade da companhia. Essa área tem como responsabilidade a segurança de todos os colaboradores da fábrica, assim como o cumprimento de normas voltadas à segurança e saúde, auxiliar a Comissão Interna de Prevenção a Acidentes (CIPA) e campanhas interna de prevenção. Também tem como responsabilidade o cumprimento de normas ambientais, como a garantia de que os recursos naturais sejam consumidos de forma consciente e preservados. Na Figura 14, é apresentado o julgamento do Gestor D, evidenciando o peso global dos critérios e o peso local dos subcritérios.

Os critérios julgados com maior importância pelo Gestor D foram o "Cr1 - Liderança" e "Cr2 - Trabalho em equipe", com peso de 0,3750. O autor Housel (2008) descreve que o trabalho em equipe facilita a execução de tarefas difíceis, pois, se um projeto longo for separado em parcelas, os indivíduos conseguem ver com maior clareza o alcance dos objetivos. Para Cooper (2012), o líder tem o dever de entender de forma intensa a missão da empresa e detectar se sua área de trabalho está colaborando para a permanência da organização no mercado. 
Morgana Klesener, Roger da Silva Wegner, Michel Barboza Malheiros, Vanessa Piovesan Rossato e Vania de Fátima Barros Estivalete

Figura 14 - Peso global dos critérios e peso local dos subcritérios sob a percepção do Gestor D

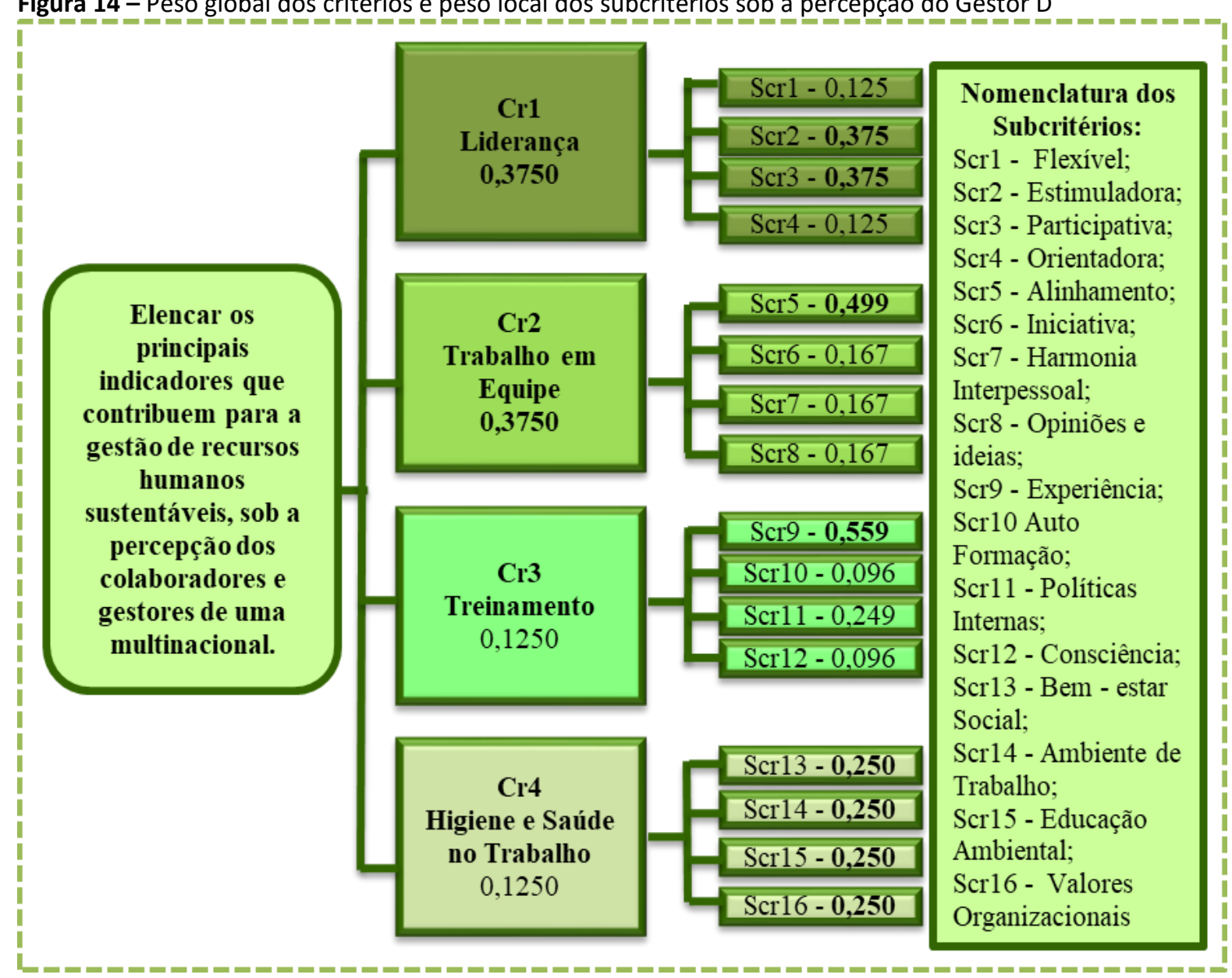

Fonte: dados da pesquisa (2018).

\title{
Para esses dois critérios o Gestor D comenta:
}

\begin{abstract}
nós temos que ter as pessoas certas que tomam as decisões corretas no momento oportuno, e são os líderes que são responsáveis pelas decisões mais estratégicas da companhia e também por otimizar suas operações [...]. A empresa, para se tornar sustentável, tem que ser competitiva [...]. Então, para que possamos ter a competitividade em alta, temos que ter pessoas mais capacitadas possíveis que consigam não só decidir, mas também destinar recurso, para que possam executar as decisões estratégicas; os recursos que eu falo são as pessoas. Na ponta de todo processo, por mais que seja tecnologia, por melhores que sejam nossos equipamentos, tem um operador, um ser humano, uma pessoa que é responsável por executar e cuidar daquilo; o líder vai conseguir alocar esse melhor recurso e vai conseguir dar o suporte para que aquelas decisões estratégicas da companhia possam vir acontecer, e, se nós não tivermos a colaboração interna, que é a colaboração entre equipes, muitas vezes, as coisas não andam. Então nós começamos a olhar de forma individualista [...]. E aí não gera sinergia, as coisas não se conectam e, muitas vezes, a engrenagem não roda, então, por isso, considero este espírito de colaboração e termos líderes capazes de dar os direcionamentos corretos como pontos importantes.
\end{abstract}

Ainda de acordo com a percepção do Gestor, percebeu-se "Cr3 - Treinamento" e "Cr4 - Higiene e saúde no trabalho", os dois com peso de 0,125. E, mesmo não estando entre os critérios mais importantes de acordo com os julgamentos, no " $\mathrm{Cr} 3$ ", encontra-se o subcritério julgado como de maior importância, o 'Scr9 - Experiência". Para o Scr9, o Gestor D fala: 
Análise da gestão de recursos humanos sustentável: um estudo em uma multinacional

[...] muitas vezes, temos ideias, temos conceitos, difundimos várias coisas internamente, mas não temos propriedade ou bagagem necessária para aquilo [...]. Isso tudo é construído através de vivência, então, para o desenvolvimento sustentável da empresa, nós precisamos ter pessoas experientes nesses temas, e, se não temos internamente, temos que trazer do mercado [...]. Nós queremos treinar, nós queremos capacitar, nós queremos difundir essas questões, mas, para isso, nós temos que ter propriedade naquilo que falamos, e nada melhor do que termos profissionais que tenham bagagem sobre isso dentro da companhia.

Na Figura 15, é possível analisar o peso global dos subcritérios julgados pelo Gestor D.

Figura 15 - Peso global dos subcritérios sob a percepção do Gestor D

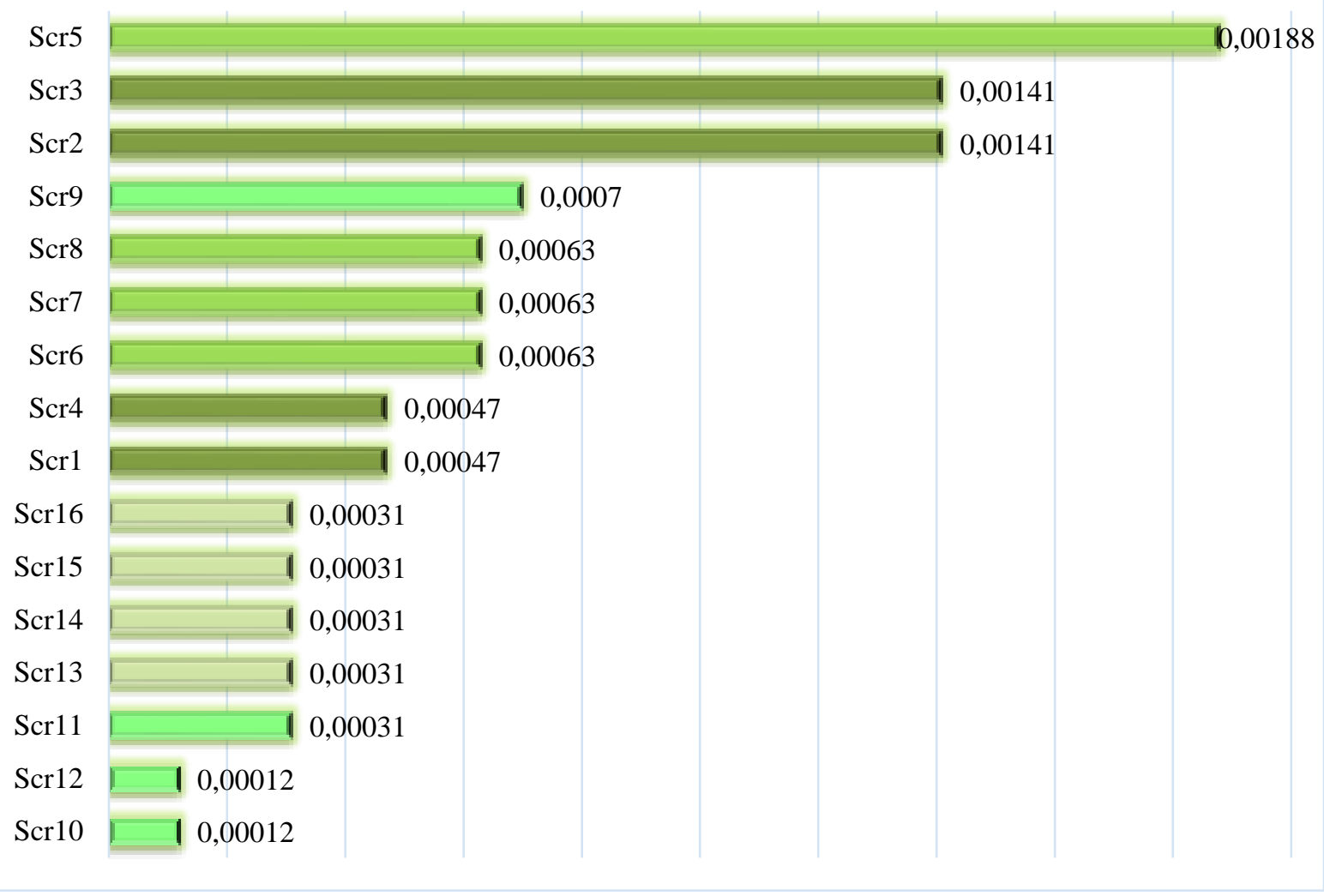

Fonte: dados da pesquisa (2018).

Diante dos dados apresentados, notou-se que o "Scr5 - Alinhamento" ficou como o mais importante entre todos, com peso de (0,00188). Neste contexto, Cooper (2012) descreve que o líder deve transmitir a seus colaboradores as informações de como a empresa está se portando, e fazer com que eles entendam a responsabilidade de sustentar a missão. Para este subcritério, o Gestor D comenta:

[...] se nós somos uma empresa que queremos ter credibilidade naquilo que vendemos, naquilo que nós pregamos, nós internamente temos que estar todos com os nossos objetivos, metas, conceitos, e aquilo que consideramos como prioridade, muito bem entendido por todos os colaboradores. Porque sem o alinhamento vai cada um para um lado, e isso faz com que não tenhamos a devida credibilidade para que a companhia possa ter esse desenvolvimento sustentável. Para cada matriz analisada, procura-se a coerência dos resultados encontrados.

Assim, na Figura 16, é possível analisar os índices de consistência desse julgamento. 
Morgana Klesener, Roger da Silva Wegner, Michel Barboza Malheiros, Vanessa Piovesan Rossato e Vania de Fátima Barros Estivalete

Figura 16 - Índice de consistência da matriz Gestor D

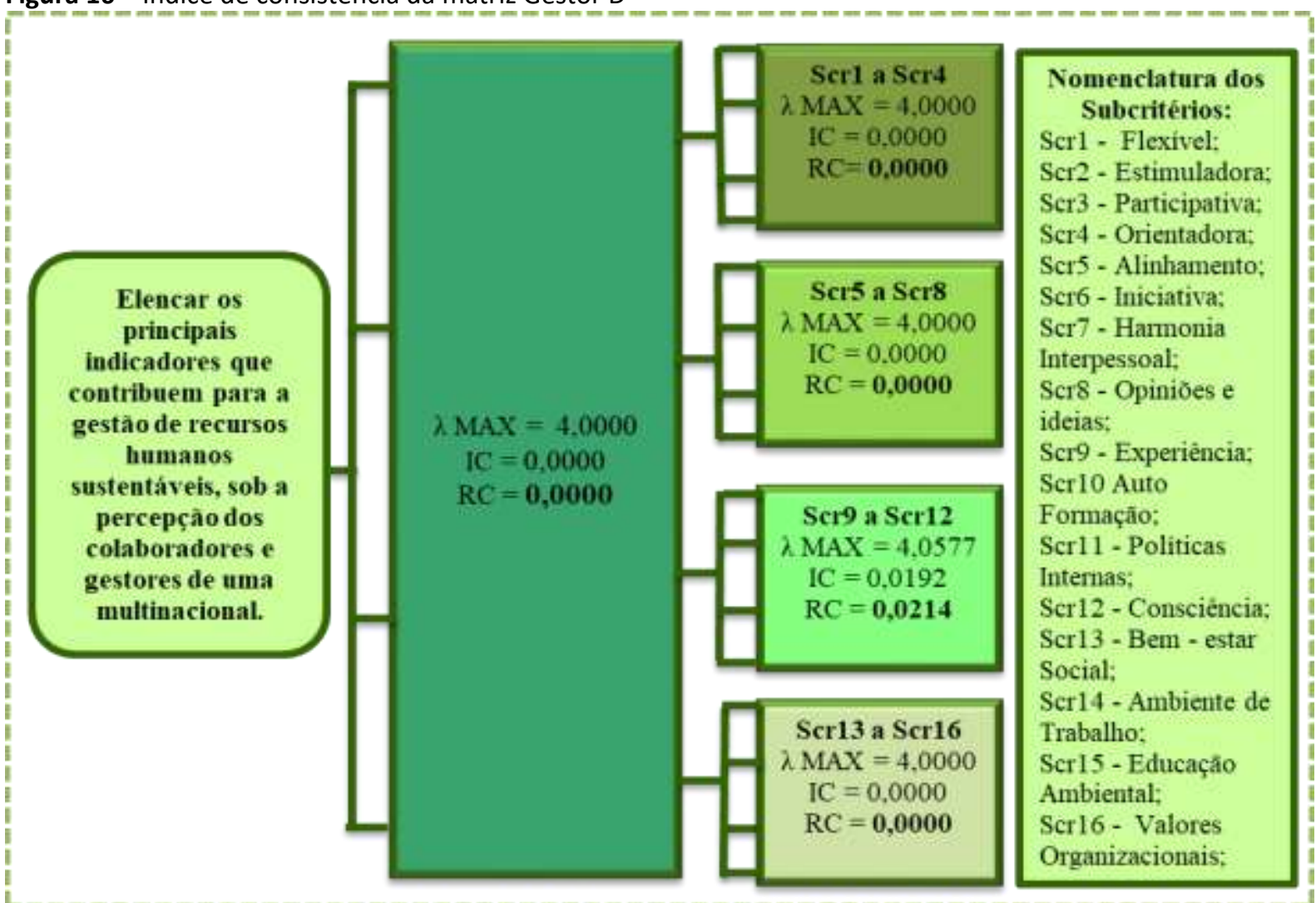

Fonte: dados da pesquisa (2018).

Por meio dos dados apresentados, notou-se que os julgamentos realizados foram menores que 0,10 , mostrando consistência dos resultados obtidos. Na Figura 17, é possível analisar resumidamente os critérios e as suas prioridades similares.

Figura 17 - Critérios destacados pelos participantes

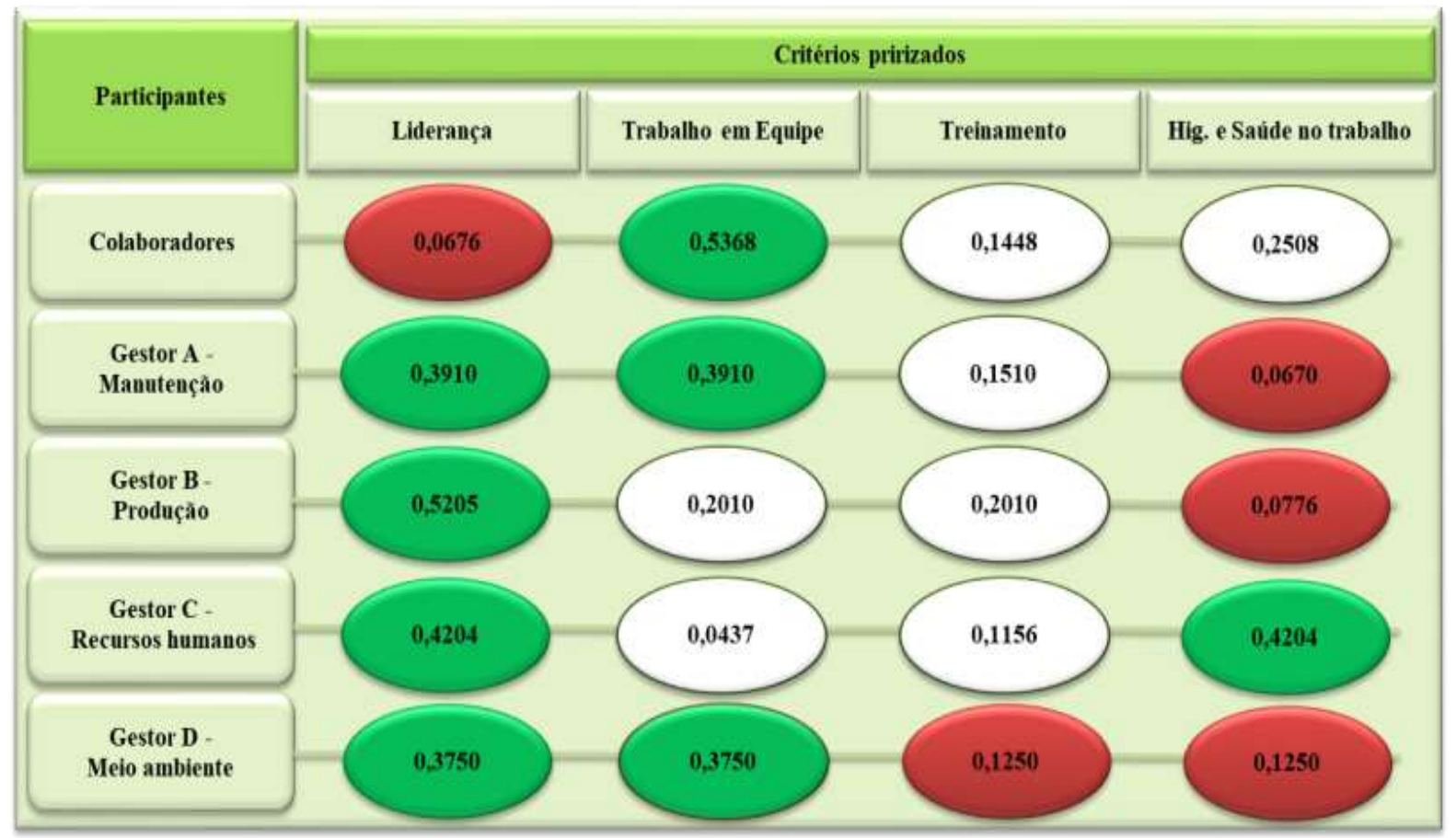

Fonte: dados da pesquisa (2018). 
De modo geral, com relação aos julgamentos realizados, pode-se perceber que os Gestores e colaboradores possuem pontos de vista diferentes. A liderança, na visão dos Gestores, é o critério que todos têm em comum como o mais importante. Os Gestores A e D entendem que o trabalho em equipe também é importante, tendo o mesmo peso que o critério liderança. $O$ Gestor $C$ entende que a higiene e saúde no trabalho também é um critério essencial para que a companhia possa crescer de forma sustentável. Já na visão dos colaboradores, o trabalho em equipe é considerado como critério mais importante, e definem a liderança como o menos importante entre os quatros critérios. Também notou -se que o critério Higiene e segurança no trabalho obteve menor grau de prioridade sob a percepção dos Gestores A, B e D.

\section{CONSIDERAÇÕES FINAIS}

O mercado tem se tornado cada vez mais competitivo, independente do ramo que a empresa trabalha, assim, buscar novidades e ter algo novo a oferecer para seus clientes é imprescindível. Ademais, a sustentabilidade vem ganhando destaque cada vez mais, e o cuidado com os recursos naturais tornou-se um ponto importantíssimo para que as empresas sejam bem-vistas. Para que isso se torne um diferencial, a área de recursos humanos pode influenciar de maneira positiva. Engajar colaboradores com o tema e desenvolver atividades que possam facilitar o entendimento- são ações simples que podem trazer grandes benefícios para a empresa.

Diante disso, o objetivo desse estudo foi elencar os principais indicadores que contribuem para a gestão de recursos humanos sustentável, sob a percepção dos colaboradores e gestores de uma multinacional. Por meio dos resultados apresentados, observou-se que- a empresa já possui uma política interna e valores voltados à sustentabilidade, o que facilita o trabalho para o desenvolvimento. Também se observa que os objetivos de sustentabilidade são cascateados em forma de meta, o que pode trazer algum desconforto aos colaboradores, de maneira que não entendam a essência das ações.

$\mathrm{Na}$ percepção dos colaboradores, o trabalho em equipe seria o critério mais importante para o desenvolvimento sustentável da organização. Dessa maneira, sugere-se que a empresa invista em capacitação de seus líderes quanto ao assunto "Equipe". Busque também treinar os gestores de forma que eles consigam desenvolver, junto de uma equipe, estratégias que mantenham a empresa em constante desenvolvimento sustentável e que possam futuramente trazer inovações.

Como sugestão de inovação, indica-se a criação de uma "Comissão Interna de Sustentabilidade", indo ao encontro das dimensões levantadas neste trabalho, assim como com as opiniões dos gestores e colaboradores. A criação de uma Comissão engloba o trabalho de um líder para com os integrantes e, diretamente, o trabalho em equipe, o que pode facilitar a obtenção dos objetivos, como também surgir novas ideias e projetos. Isso também auxilia no melhor entendimento do assunto e das metas da companhia, como também no desenvolvimento de pequenas ações para conscientização dos demais colaboradores.

Como limitação deste trabalho, se destacam os resultados obtidos apenas na realidade da unidade investigada. Ademais, para estudos futuros, sugere - se que seja realizada uma pesquisa que contemple mais unidades em diversos países, visando compreender a percepção dos gestores e colaboradores sobre a temática investigada. 
Morgana Klesener, Roger da Silva Wegner, Michel Barboza Malheiros, Vanessa Piovesan Rossato e Vania de Fátima Barros Estivalete

\section{REFERÊNCIAS}

ALCARAZ, J. M.; SUSAETA, L.; SUARÉZ, E.; COLÓN, C.; GUTIÉRREZ-MARTINEZ, I.; CUNHA, R.; LEGUIZAMÓN, F.; IDROVO, C.; EISZ, N.; CORREIA, M. F.; PIN, J. R. The human resources management contribution to social responsibility and environmental sustainability: explorations from Ibero-America. The International Journal of Human Resource Management, v. 30, n. 22, p. 3166-3189, 2017. DOI: 10.1080/09585192.2017.1350732.

ALVARES, K. P.; SOUZA, I. M. Sustentabilidade na gestão de pessoas: práticas e contribuições às organizações. Revista Gestão Organizacional, v. 9, n. 2, p. 24-38, 2016. DOI: doi.org/10.22277/rgo.v9i2.3285.

BARBIERI, U. F. Gestão de pessoas nas organizações: conceitos básicos e aplicações. São Paulo: Atlas, 2016.

BARSANO, P. R.; BARBOSA, R. P. Higiene e segurança do trabalho. 1 ed. São Paulo: Érica, 2014.

COOPER, A. A. Como ser um líder. São Paulo: Cengage Learning, 2012.

CURY, A. Organizações e métodos: uma visão holística. 8. ed. São Paulo: Atlas, 2007.

D'AMORIM, A. R. F. F; Gestão de Recursos Humanos em organizações sustentáveis: análise à luz do Global Reporting Initiative e da Administração Renovada. 2009. 188 f. 2009. Tese de Doutorado. Dissertação (Mestrado em Administração) - Programa de Pós-Graduação em Administração, Universidade Federal da Paraíba, João Pessoa, 2009.

DIAZ-CARRION, R; LÓPEZ-FERNÁNDEZ, M; ROMERO-FERNANDEZ, P. M. Constructing an index for comparing human resources management sustainability in Europe. Human Resource Management Journal, v. 31, n. 1, p. 120-142, 2020. DOI: 10.1111/1748-8583.12286.

FREITAS, W. R. S.; SOUZA, M. T. S.; TEIXEIRA, A. A.; JABBOUR, C. J. C. Produção científica sobre gestão de recursos humanos e sustentabilidade: síntese e agenda de pesquisa. Revista de Ciências da Administração, v. 15, n. 36, p. 11-28, 2013. DOI: 10.5007/21758077.2013v15n36p11.

GRACIOSO, L. F. Liderança empresarial: competências que inspiram, influenciam e conquistam resultados. 1. ed. São Paulo: Atlas, 2009.

HARDINGHAM, A. Trabalho em equipe. 1 ed. São Paulo: Ed. Nobel, 2000.

HOUSEL, D. J. Equipes: gerenciando para o sucesso. Cengage Learning, 2008.

JABBOUR, C. J. C.; SANTOS, F. C. A; NAGANO, M. S. Análise do relacionamento entre estágios evolutivos da gestão ambiental e dimensões de recursos humanos: estado da arte e survey em empresas brasileiras. Revista de Administração da USP, v. 44, n. 4, p. 342-364, 2009. 
KRAMER, M. R.; PORTER, M. E. Estrategia y sociedad: el vínculo entre ventaja competitiva y responsabilidad social corporativa. Harvard Business Review, v. 84, n. 12, p. 42-56, 2006.

LACOMBE, F. J. M. Recursos humanos. 2. ed. São Paulo: Saraiva, 2011.

MARRAS, J. P. Administração de recursos humanos: do operacional ao estratégico. 15. ed. São Paulo: Saraiva, 2016.

MASCARENHAS, A. O.; BARBOSA, A. C. Q. Gestão de recursos humanos sustentável e responsabilidade socioambiental: Uma agenda para debates. Revista de Administração de Empresas, v. 59, n. 5, p. 353-364, 2019. DOI: 10.1590/S0034-759020190505.

MIN, H. Evaluating the comparative service quality of supermarkets using the analytic hierarchy process. Journal of Services Marketing, v. 24, n. 4, p. 283-293. 2010. DOI: 10.1108/08876041011052999.

OLIVEIRA, D. P. R. Planejamento Estratégico: conceitos, metodologia, práticas. 23. ed. São Paulo: Atlas, 2007.

PARENTE, T. C.; FISCHER, A. L. A relação entre recursos humanos e sustentabilidade como tema emergente: Uma análise bibliométrica. Revista Alcance, v. 21, n. 3, p. 398-421, 2015. DOI: 10.14210/alcance.v21n3.p398-421.

REN, S.; TANG, G; JACKSON, S. E. Green human resource management research in emergence: A review and future directions. Asia Pacific Journal of Management, v. 35, n. 3, p. 769-803, 2018. DOI: 10.1007/s10490-017-9532-1.

REZAEE, Z. Corporate sustainability: Theoretical and integrated strategic imperative and pragmatic approach. The Journal of Business Inquiry, v. 16, n. 1, p. 60-87, 2017.

RIMANOCZY, I.; PERSON, T. Role of HR in the new word of sustainability. Industrial and Comercial Training, v. 42, n. 1, p. 11-17, 2010.

ROBBINS, S.P. Comportamento organizacional. 11. ed. São Paulo: Pearson Prentice Hall, 2005.

SAATY, T. L.; OZDEMIR, M. Negative priorities in the analytic hierarchy process. Mathematical and Computer Modelling, v. 37, n. 9-10, p. 1063-1075, 2003. DOI: 10.1016/S0895-7177(03)00118-3.

SAATY, T. L. Scales from measurement-not measurement from scales. In: Proceedings of the 17th International Conference on Multiple Criteria Decision Making, Whistler, BC Canada, p. 6-11, 2004.

SAATY, T. L. Relative measurement and its generalization in decision making why pairwise comparisons are central in mathematics for the measurement of intangible factors the analytic hierarchy/network process. RACSAM-Revista de la Real Academia de Ciencias 
Morgana Klesener, Roger da Silva Wegner, Michel Barboza Malheiros, Vanessa Piovesan Rossato e Vania de Fátima Barros Estivalete

Exactas, Fisicas y Naturales. Serie A. Matematicas, v. 102, n. 2, p. 251-318, 2008. DOI: 10.1007/BF03191825.

SAATY, T. L.; SHIH, H-S. Structures in decision making: On the subjective geometry of hierarchies and networks. European Journal of Operational Research, v. 199, n. 3, p. 867872, 2009. DOI: 10.1016/j.ejor.2009.01.064.

SROUFE, L. A; COFFINO, B; CARLSON, E. A. Conceptualizing the role of early experience: Lessons from the Minnesota longitudinal study. Developmental Review, v. 30, n. 1, p. 36-51, 2010. DOI: 10.1016/j.dr.2009.12.002. 